\title{
Estimating the optimum size of a tidal array at a multi-inlet system considering environmental and performance constraints
}

\author{
Corresponding Author: Eduardo González-Gorbeña ${ }^{1}$ \\ E-mail: egeisenmann@ualg.pt \\ Telf.: +351915113242
}

André Pacheco ${ }^{1}$

E-mail: ampacheco@ualg.pt

\section{Theocharis A. Plomaritis ${ }^{1,2}$}

E-mail: tplomaritis@ualg.pt haris.plomaritis@uca.es

\section{Óscar Ferreira ${ }^{1}$}

E-mail: oferreira@ualg.pt

\section{Cláudia Sequeira ${ }^{1}$}

E-mail: cdsequeira@ualg.pt

${ }^{1}$ Centre for Marine and Environmental Research (CIMA), Universidade do Algarve (UAlg), Edifício 7, Campus de Gambelas Faro, 8005-139, Portugal.

${ }^{2}$ Faculty of Marine and Environmental Science, Department of Earth Science, Universidad de Cádiz, Campus Río San Pedro (CASEM), Puerto Real 11510, Cádiz, Spain.

Doi: https://doi.org/10.1016/j.apenergy.2018.09.204

\begin{abstract}
This paper investigates the optimum tidal energy converter array density at a tidal inlet by applying surrogate-based optimisation. The SBO procedure comprises problem formulation, design of experiments, numerical simulations, surrogate model construction and constrained optimisation. This study presents an example for the Faro-Olhão Inlet in the Ria Formosa (Portugal), a potential site for tidal in-stream energy extraction. A $35 \mathrm{~kW}$ Evopod $^{\mathrm{TM}}$ floating tidal energy converter from Oceanflow Energy Ltd. has been used for array size calculations considering two design variables: 1) number of array rows, and 2) number of tidal energy converter per row. Arrays up to 13 rows with 6 to 11 tidal energy converters each are studied to assess their impacts on array performance, inlets discharges and bathymetry changes. The analysis identified the positive/negative feedbacks between the two design variables in real case complex flow fields under variable bathymetry and channel morphology. The non-uniformity of tidal currents along the array region causes the variability of the resource in each row, as well as makes it difficult to predict the resultant array configuration interactions. Four different multi-objective optimisation models are formulated subject to a set of performance and environmental constraints.
\end{abstract}




\section{Pre-print}

Results from the optimisation models imply that the largest array size that meets the environmental constraints is made of 5 rows with 6 tidal energy converter each and an overall capacity factor of $11.6 \%$ resulting in an energy production of $1.01 \mathrm{GWh}_{\text {.year }}{ }^{-1}$. On the other hand, a higher energy production (1.20 GWh.year $\left.{ }^{-1}\right)$ is achieved by an optimum array configuration, made of 3 rows with 10 tidal energy converters per row, which maximises power output satisfying environmental and performance restrictions. This optimal configuration permits a good level of energy extraction while having a reduced effect on the hydrodynamic functioning of the multiinlet system. These results prove the suitability and the potential wide use of the surrogate-based optimisation method to define array characteristics that enhance power production and at the same time respect the environmental surrounding conditions.

Keywords: Tidal stream resource; turbine array layout; surrogate based optimisation; tidal current turbines; hydro-morphodynamic modelling; marine renewable energy.

\section{Introduction}

Tidal stream energy harvesting consists in extracting part of the kinetic energy from the natural tidal currents to generate electricity. In a coastal lagoon system, the above process can be very productive due to the ebb/flood circulation amplification at the tidal inlets. Tidal Energy Converters (TECs) are used for this purpose and, currently, there are numerous types of technologies being proposed and tested at different technology readiness levels with the most advanced devices being at TRLs of 7-8 [1]. Tidal energy has the advantage of being a renewable source of energy with high density, which makes it possible to produce electricity from low flow speeds if compared, for example, with wind energy. One of the advantages of tidal energy with respect to other renewable energy forms is that tides are extremely predictable. It is therefore simple to estimate power production at a particular time, a key aspect to optimise energy distribution systems. For a detailed and complete overview of the tidal energy sector refer to [1].

The tidal energy potential at shallow water estuaries and coastal lagoon systems can be exploited using small-scale TEC devices. Shallow near shores provide economic advantages during TECs deployment and maintenance activities because they are in close vicinity to land, providing advantages in the maintenance and power distribution logistics. These conveniences can translate into opportunities for coastal communities to adopt this form of energy generation and diverse their sustainable and renewable energy matrix. Recent resource assessment studies have shown the potential for tidal energy extraction and/or for device validation of several coastal areas at the UK, Ireland, Spain and Portugal such as the Severn estuary (Wales, UK) [2], Shannon Estuary (Ireland) [3], Rias Baixas (Galicia, Spain) [4] and Ria Formosa (Algarve, Portugal) [5].

On the other hand, there are drawbacks that need to be overcome, mainly related with the coastal environment. Usually, potential regions for energy harvesting are also sensitive natural areas, highly dynamic, with a rich biological diversity and enclose a wide range of uses and stakeholders (e.g. commercial and recreational activities). Any modification introduced into these fragile environments can have the potential to alter the system's equilibrium [6]. The direct consequence of installing and operating a TEC is the alteration of the system's hydrodynamics. As a result of the modification of the hydrodynamic field, other environmental impacts can arise, such as: decrease tidal flooding [6], modify population distribution and dynamics of marine organisms [7], alter water quality [8], increase noise pollution [9], transform marine habitats [10], increase mixing in systems where salinity/temperature gradients are well-defined [10], and affect the transport and deposition of sediments [11]. The effect of TECs on sediment dynamics has been the subject of intense research in the last years by means of numerical modelling. Apart from 


\section{Pre-print}

the study of [11] for São Marcos Bay, Brazil, all of the research focuses on UK (e.g. [12], [13] [57],) and France [14] tidal stream energy sites. All studies conclude that TECs presence affect in some extent sediment dynamics, and that the magnitude of the impact depends on tides, the sedimentological characteristics of the site and the amount of energy extracted (i.e. the installed power capacity of the TEC array). Moreover, Robins et al. [12] and Fairley et al. [13] highlight the importance of considering wave shear stresses when assessing morphodynamic impact of tidal turbines. At complex coastal systems, such as multi-inlet coastal lagoons, influences on sediment dynamics will not only be felt on the vicinity of the TEC units but can also affect the global hydrodynamic pattern or the tidal prism of other inlets.

In order to assess the commercial feasibility of a tidal energy project, first, the optimal size and TECs arrangements should be obtained. The drag exerted to the flow by the array depends on blockage, which relates with the number of TEC units and their distribution within the array. High blockage ratios can significantly affect the propagation of the tidal wave, affecting water levels and flow velocities well beyond the location of the tidal array. Therefore, for a given tidal channel, there is an optimum number of TECs to maximise array efficiency at a desired blockage ratio, as investigated by several authors in uniform rectangular channels using one-dimensional theoretical models based on the actuator disk theory [15], [16], [17], [18], [19] or by means of semi-analytical methods [20]. However, when it comes to real case scenarios with complex flows the aforementioned models, due to their derivation assumptions, are not able to adequately represent the flow surrounding the tidal arrays. Even less to assess their effects on the complex processes and feedback mechanisms of the whole system [21], [22]. For this purpose, numerical modelling of the entire coastal system is a useful tool to simulate case scenarios and predict the effects that energy extraction will have on the overall system's hydrodynamics, as well as on other processes like sediment transport pathways and/or water quality issues.

In the cases where time-consuming numerical simulations are involved, Surrogate-Based Optimisation (SBO) revealed itself as an attractive optimisation technique. In the literature, there are numerous applications of SBO techniques in various fields of knowledge [23]. Recently, SBO methods have been applied to solve the TEC array layout problem in idealised channels aiming to maximise the overall capacity factor of the array subject to economic and geometric constraints [24], as well as to environmental restrictions [25]. The SBO approach consists in approximating a mathematical function, i.e. a surrogate or a metamodel, to existing data or to a function that is expensive (i.e. time-consuming) to evaluate and has no analytical form. Computational simulations are a remarkable example, where an individual run can take hours or even days to complete. The mathematical function provides a response (i.e. dependant variable) as a function of a vector of design parameters (i.e. independent variables), in which its execution computational time is instantaneous. Once a validated surrogate model is built, it can be incorporated into a mathematical optimisation model. Further details on the SBO approach can be obtained in [26].

This paper presents a case study for the complex multi-inlet system of Ria Formosa coastal lagoon (Algarve, Portugal), where the SBO approach is employed to estimate the optimal size of a tidal array for Faro-Olhão Inlet. Several optimisation models are formulated to optimise array characteristics as a function of two design variables, i.e. number of array rows and TECs per row, while ensuring a certain array performance level and minimising detrimental impacts on the lagoon hydrodynamics and morphological processes. As far as the author's know, there has not been yet published any paper where the SBO approach has been used to estimate the optimum size of a tidal array at a potential tidal site. 


\section{Pre-print}

The remainder of this paper is organized as follows. The paper introduces the main characteristics of the study region (Section 2), describes the methodology approach, including aspects of the tools used, the numerical model set-up and validation, and details the implementation of the SBO method (Section 3), presents the results obtained (Section 4), together with a discussion of these results (Section 5), and presents the main conclusions (Section 6).

\section{Site description}

The Ria Formosa is a multi-inlet barrier system located in southern Portugal (Fig. 1), comprising five islands and two peninsulas, separated by six tidal inlets, salt marshes, sand flats and a complex network of tidal channels. Two of the inlets are stabilised (Faro-Olhão and Tavira inlets); and the other four are natural (Ancão Armona, Fuseta and Lacém). The tides in the area are semidiurnal with typical average astronomical ranges of $2.8 \mathrm{~m}$ for spring tides and $1.3 \mathrm{~m}$ for neap tides. A maximum tidal range of $3.5 \mathrm{~m}$ can be reached during equinoctial tides [27], [28]. Wave climate in the area is moderate (an offshore annual mean significant wave height, $\mathrm{H}_{\mathrm{s}}$, of $\sim 1 \mathrm{~m}$ and peak period, $\mathrm{T}_{\mathrm{p}}$, of $8 \mathrm{~s}$, with storms characterized by $\mathrm{H}_{\mathrm{s}}>3 \mathrm{~m}$ ). Approximately $71 \%$ of waves approach from the W-SW, with about $23 \%$ coming from E-SE [29]. The lagoon is generally well mixed vertically, with no evidence of persistent or widespread haline or thermal stratification [30]. Due to reduced freshwater inputs and elevated tidal exchanges, the salinity values usually close to those observed at adjacent coastal ocean waters [30].

The storm surges in the area are relatively small due to the narrow continental shelf. During extreme storm conditions the surge levels are estimated to reach values close to $0.6 \mathrm{~m} \mathrm{[27].} \mathrm{For} \mathrm{a}$ typical storm with a significant wave height of $4 \mathrm{~m}$ the associated storm surge is on the order of $0.25 \mathrm{~m}$ (with a rise and lowering - surge wave - often longer than one day). An analysis conducted for a Portuguese lagoon with similar characteristics shows that such surge levels can imply an absolute maximum change in peak velocities of $16 \%$ during an extreme scenario (i.e. important storm surge during spring tides), however, the probability occurrence of these events are very low [31]. 


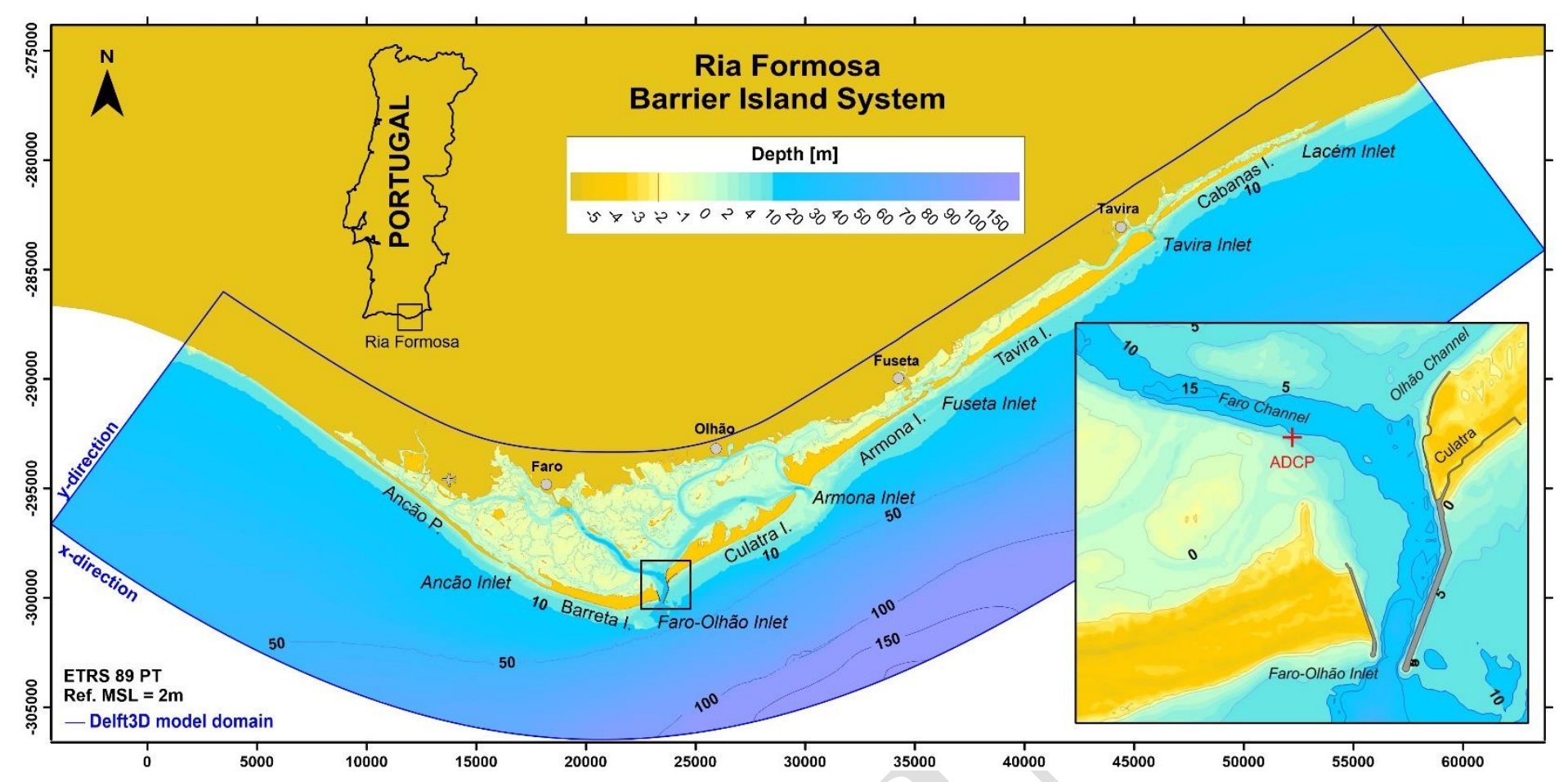

Fig. 1 - Location map of the study region. Zoom rectangle shows the Faro-Olhão Inlet, the location for TEC array deployment, and the red cross shows were the ADCP was deployed.

Tide and wind forcing together with morphological and morphodynamics characteristics of the Ria Formosa inlets control water exchange rates and residual flows of the lagoon [32]. Morphological changes (natural or human) in any of the inlets can modify tidal prism on any other inlet of the system, especially on the inlets of the western sector which have a significant interplay between them [32]. These alterations can have an important repercussion on some of the economic activities of the region such as aquaculture, salt farming, fishing, shellfish farming, shipping, mining, and tourism. These activities have local and regional importance, and the shellfish farming assumes national impact representing $60 \%$ of the total Portuguese production. Such a congregation of different activities makes the management of the Ria Formosa a very difficult task for the region's decision-makers and any relevant change in the hydrodynamics of the system can affect and disturb these activities as a cascade effect.

Measurements of the tidal prism performed between 2006 and 2007 for each inlet of the Ria Formosa reveal a clear circulation pattern between Faro-Olhão and Armona inlets [33]. The two inlets present ebb-dominated behaviour (i.e. higher mean ebb velocity associated with shorter ebb duration). However, at the Faro-Olhão Inlet, the flood prism is considerably greater than the ebb prism. The sediment transport direction is strongly landward (flood) directed as evidenced by the regular dredging operations required to maintain the channel navigability. In contrast, the Armona Inlet is always ebb-dominant and capable of flushing sediment seaward under fair-weather conditions, especially during spring tides. These two major inlets represent almost $90 \%$ of the total prism of the Ria Formosa. The interconnection between both inlets is particularly active during spring tides (Faro-Olhão 61\% and Armona 23\% of overall Ria Formosa tidal-prism), but is reduced during neap-tides when the inlets drain the basin more independently (Faro-Olhão $45 \%$ and Armona $40 \%$ of overall tidal-prism).

Ria Formosa has a long history of tidal energy harvesting, from the XII to the XX century tide mills have been operating in its channels taking advantage of the periodic fall and rise of the water level. Pacheco et al. [5] determined for a specific cross section of the Faro-Olhão Inlet a 


\section{Pre-print}

mean and maximum potential extractable power of $0.4 \mathrm{~kW} \cdot \mathrm{m}^{-2}$ and $5.7 \mathrm{~kW} \cdot \mathrm{m}^{-2}$, respectively. By means of a 2DH numerical model, González-Gorbeña et al. [34] assessed the tidal resource for the whole Faro-Olhão Inlet obtaining tidal current velocities greater than $0.7 \mathrm{~m} . \mathrm{s}^{-1}$ for more than $60 \%$ of the time at the inlet throat.

\section{Methodological approach}

\subsection{Numerical modelling}

\subsubsection{Model concept and set-up}

The Delft3D is employed as a tool for implementing the SBO methodology (detailed in Section 3.2) to define the optimum TEC array size of the Faro-Olhão Inlet taking into consideration both the resource (i.e. tidal energy) and the environment (i.e. consequences). The model is adopted in a depth averaged mode (2DH), since there is a limited fresh water input into the lagoon and negligible salinity and temperature gradients. The hydrodynamic model is coupled with a morphodynamic model to approximate bed changes as function of sediment transport rates, as exemplified in other studies [35], [36], [37].

The model domain is discretised with a curvilinear orthogonal grid in spherical coordinates that follows the general cuspate shape of the lagoon (Fig. 1), and extends approximately over 60 $\mathrm{km}$ alongshore and $18 \mathrm{~km}$ cross-shore. The domain is discretised with $1100 \times 462$ grid points. The grid resolution varies between $\Delta x=750 \mathrm{~m}, \Delta y=175 \mathrm{~m}$ at the offshore area and $\Delta x=20 \mathrm{~m}$, $\Delta y=15 \mathrm{~m}$ over the inlet areas, where the grid was refined in order to capture the complex and rapid changing morphology. The model bathymetry was built using the high resolution LiDAR topo-bathymetry performed in 2011, coupled with bathymetric data from the Faro Port Authority and with 2016 bathymetric surveys performed under the SCORE project [38]. The LIDAR and SCORE bathymetries are available online (open-access) at the SCORE project database [39]. Bottom roughness was assigned to each grid point using the White-Colebrook's formulation [40]. At the ocean boundary, the sea level was prescribed using the main tidal constituents (Table 1). The models time step is $30 \mathrm{~s}$, which, according to the Courant-Friedrichs-Levy criterion [41], is sufficiently small to ensure numerical stability. For calibration and validation purposes, the effect of wind was considered in the simulations as a spatially uniform forcing. The wind time series were retrieved from the meteorological station located in Faro's airport. Due to the low local wave climate and the narrow nature of the Faro-Olhão Inlet the offshore wave forcing does not significantly affect the array deployment area. For the purpose of this study, the effects of waves and storm surge are not considered in the numerical simulations.

Table 1 - Principal Ria Formosa tidal constituents from TOPEX/POSEIDON-7.2 DATA [64].

\begin{tabular}{lcc}
\hline Harmonic constant & Amplitude $(\mathbf{m})$ & Phase $\left(^{\circ}\right)$ \\
\hline M2 & 0.995 & 56.58 \\
S2 & 0.365 & 82.57 \\
N2 & 0.211 & 39.87 \\
K2 & 0.098 & 78.67 \\
K1 & 0.069 & 49.75 \\
O1 & 0.058 & 310.45 \\
P1 & 0.020 & 43.78 \\
Q1 & 0.017 & 260.98 \\
MF & 0.001 & 261.36 \\
MM & 0.001 & 191.43 \\
\hline
\end{tabular}




\section{Pre-print}

\subsubsection{Hydro-morphodynamic model calibration and validation}

Two sets of hydrodynamic data were used for the hydrodynamic model calibration and validation process. Water levels and flow velocities were obtained with a bottom-mounted ADCP (Nortek Signature 1000). The ADCP (Fig. 1) was deployed at a mean water depth of $7.7 \mathrm{~m}$ (Fig. 1) from $03 / 11 / 2016$ to $17 / 11 / 2016$ and $14 / 12 / 2016$ to $02 / 12 / 2017$ and was set to measure average velocities every $60 \mathrm{~s}$ for time intervals of $600 \mathrm{~s}$ at $0.2 \mathrm{~m}$ vertical cells. Part of those time series have been used to calibrate and validate the model results (Fig. 2). Peak spring flood and ebb tidal current velocities contour maps are illustrated in Fig. 3.
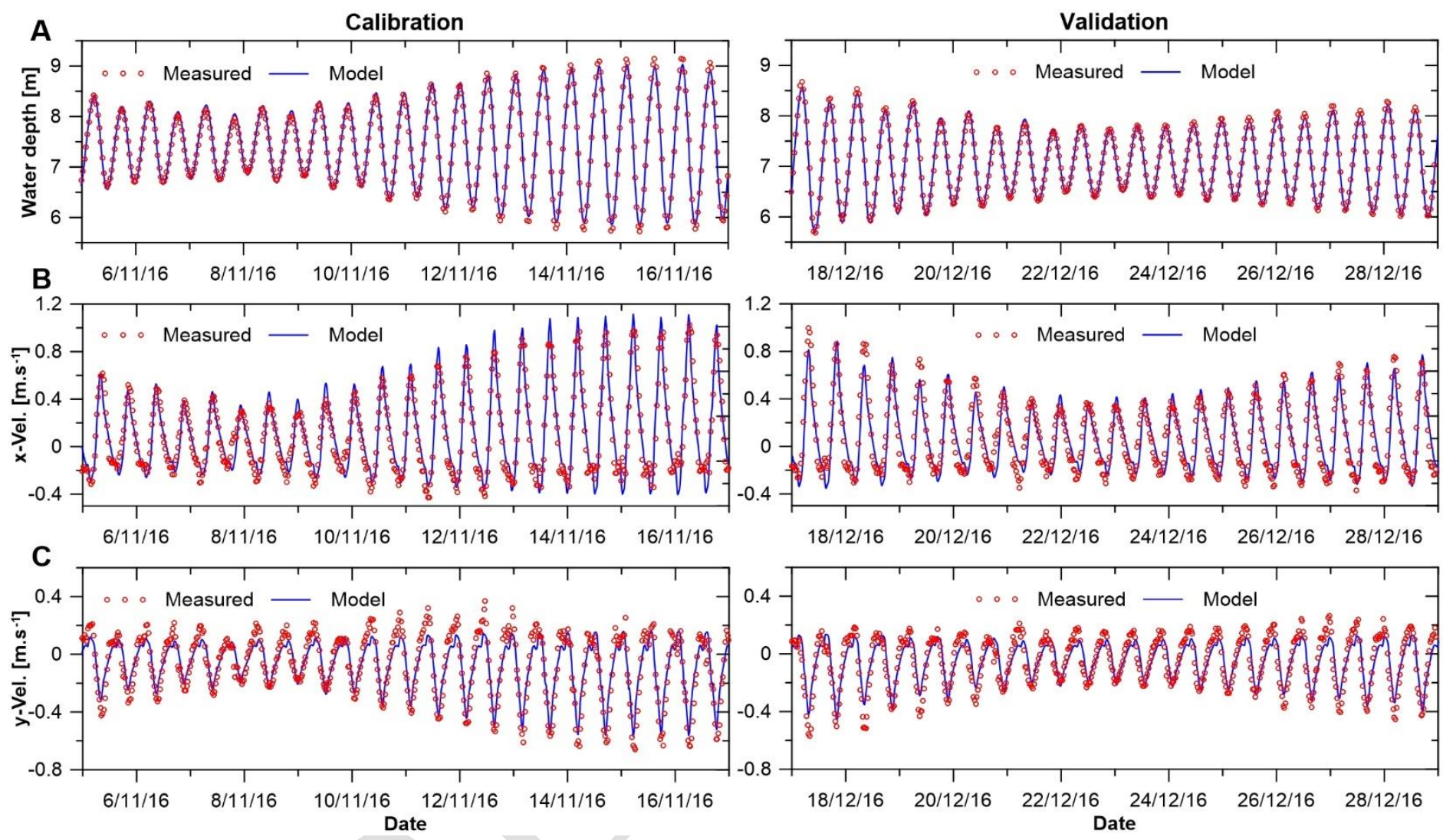

Fig. 2 - Water depth (A), Easting velocity component (B) and Northing velocity component (C) comparisons between measured data (ADCP Nortek Signature1000) and model results (Delft3D) for: calibration (left) and validation data sets (right). 


\section{Pre-print}
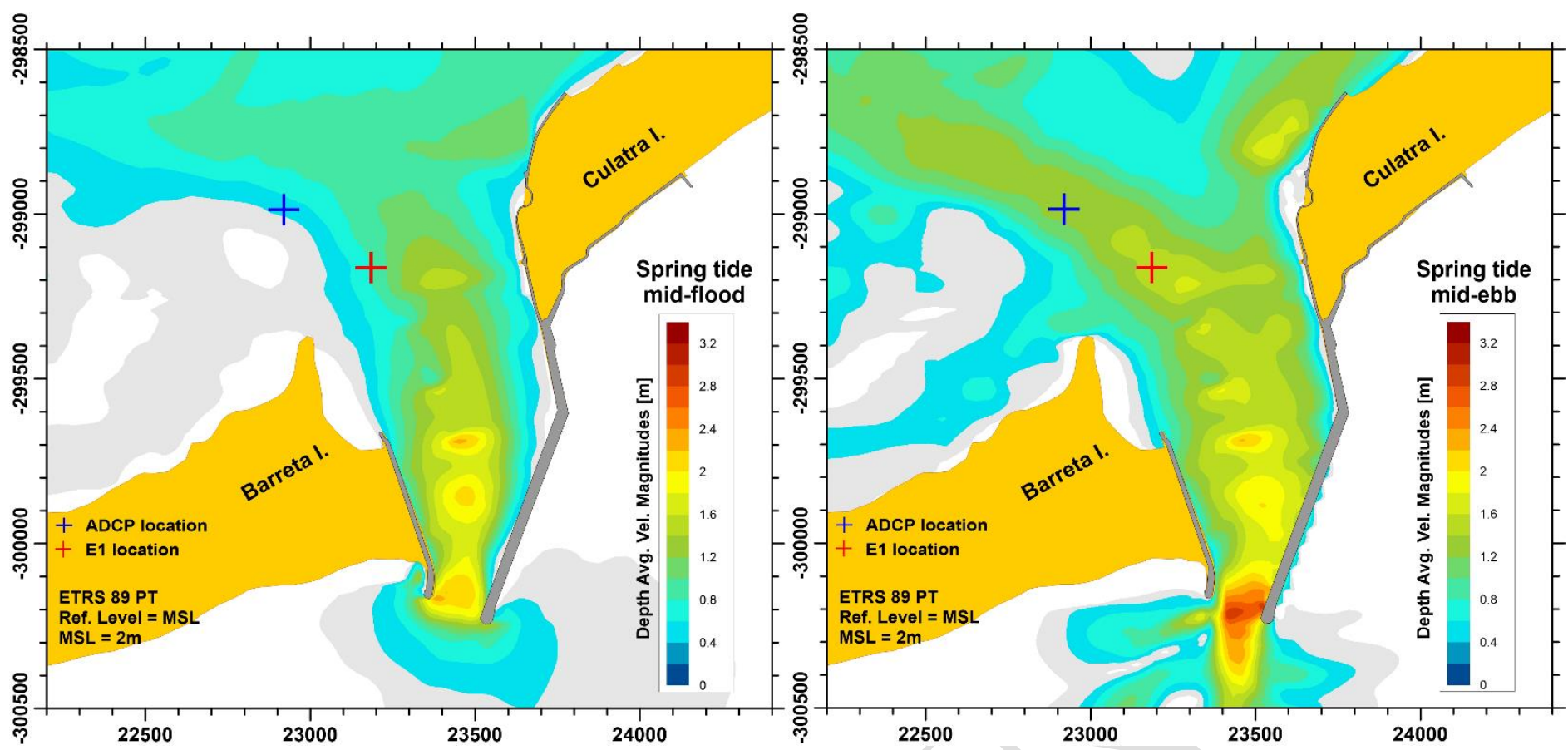

Fig. 3 - Tidal current velocities contours for spring tide mid flood (left) and mid ebb (right).

To assess the model performance several statistical parameters have been calculated. Table 2 summarizes the goodness-of-fit statistics of the model for both calibration and validation data sets. Observing bias values, it is clear that the model output tends to slightly overestimate water levels and underestimate Easting velocity components. For the calibration model, Northing velocity amplitudes show the poorest agreement of the three variables but still with Index of Agreement (IA) and Correlation Factor (R) values around 0.9. In general terms, and taking into account all statistical parameters, the model performance is considered very good. Notice that the underestimation of flow velocities, specially peak flows, will have an implication on the power outputs estimation, which will also be underestimated as it is proportional to the cube of the flow velocity. Furthermore, morphological changes are more sensitive to errors in velocities. Differences between measured and computed data could be related to uncertainties in bathymetric data due to a lack of accurate information of all recent dredging volumes. Possibly also related to a grid size with a degree of refinement not enough to characterize all channels features. Additionally, differences could be also related to the inlet characteristics (composed by the curved ocean and lagoon coast and jetties). Despite the high degree of grid refinement, the Faro-Olhão Inlet presents a high degree of complexity, which it makes difficult to characterise using a curvilinear finite difference grid.

Table 2 - Model Goodness-of-Fit Statistics. Standard Deviation of Residuals (SDR); Normalised Root Mean Square Error (NRMSE), Index of Agreement (IA) and Correlation Coefficient (R).

\begin{tabular}{|c|c|c|c|c|c|c|}
\hline \multirow[b]{2}{*}{ Statistics } & \multicolumn{3}{|c|}{ Calibration } & \multicolumn{3}{|c|}{ Validation } \\
\hline & $\begin{array}{c}\text { Water Level } \\
{[\mathrm{m}]}\end{array}$ & $\mathrm{x}$-vel $\left[\mathrm{m} . \mathrm{s}^{-1}\right]$ & $y$-vel $\left[\mathrm{m} . \mathrm{s}^{-1}\right]$ & $\begin{array}{c}\text { Water Level } \\
{[\mathrm{m}]}\end{array}$ & $x$-vel [m] & $y$-vel $\left[{\left.\mathrm{m} . \mathrm{s}^{-1}\right]}^{-1}\right.$ \\
\hline Bias & 0.0006 & -0.016 & -0.007 & 0.018 & -0.009 & 0.003 \\
\hline SDR & 0.078 & 0.130 & 0.116 & 0.085 & 0.112 & 0.072 \\
\hline NRMSE* & 0.007 & 0.017 & 0.0226 & 0.026 & 0.074 & 0.070 \\
\hline $\mathrm{IA}^{*}$ & 0.998 & 0.961 & 0.898 & 0.997 & 0.972 & 0.959 \\
\hline $\mathrm{R}^{*}$ & 0.995 & 0.929 & 0.901 & 0.994 & 0.946 & 0.947 \\
\hline
\end{tabular}




\section{Pre-print}

Morphological predictions were simulated with the use of the morphological acceleration parameter (MorFac), assuming the linear hydrodynamic forcing during one morphological step [35], [42]. Regarding the morphodynamic validation, model results were compared with annual estimates of sediment budgets obtained from long-term data collected at the Faro-Olhão Inlet over the period of 1962-2001 [33]. Pacheco et al. [33] estimated the annual sediment budget of FaroOlhão Inlet (and adjacent areas) from volume computation using available bathymetric data, topography and dredging reports. The authors compared the model results with two periods (e.g. 1962-1978 and 1978-2001), quantifying different sources of uncertainty. The relative advantage of using long-term sediment budget data for model validation, instead of short term detailed bed level changes, is that results are relatively independent of the initial model bathymetry and more representative of the general sediment transport processes and patterns. Two characteristic areas of the Faro-Olhão Inlet were selected for calculating the sediment volume changes (Fig. 4): (i) the flood-tidal delta area $\left(V_{f}\right)$ and (ii) the inlet area $\left(V_{i}\right)$. The adopted approach was developed by combining the use of long-term data to identify sediment transport patterns for model calibration purposes [43], with the sediment budget concept for pre-defined neighbouring cells [44].

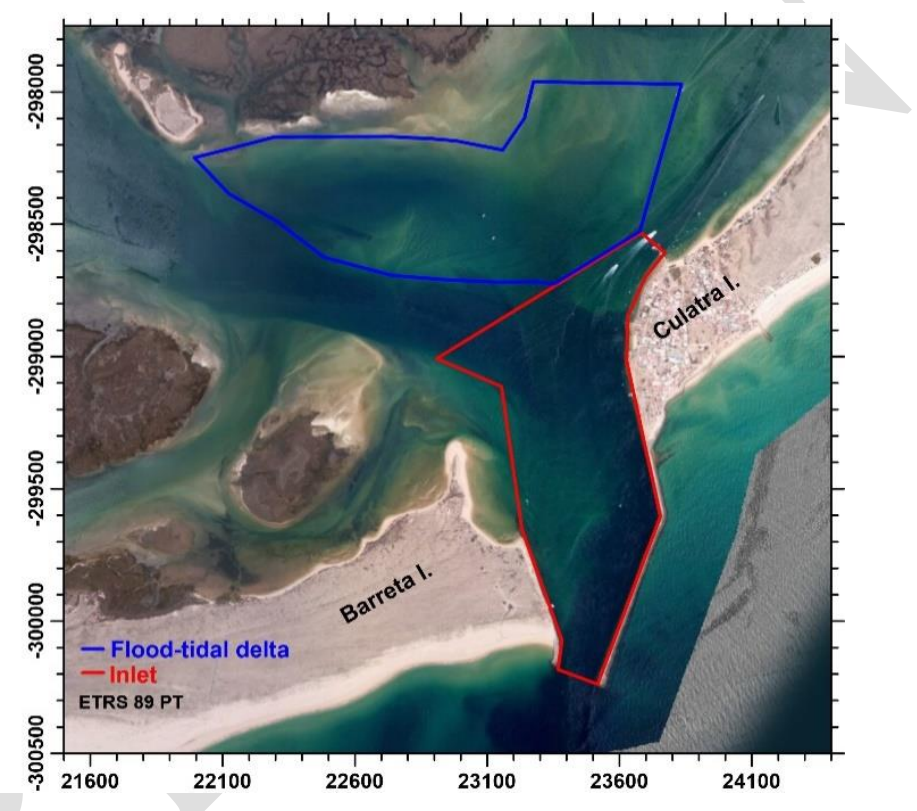

Fig. 4 - Aerial photo of the Faro-Olhão Inlet with the outline of the flood tidal delta $\left(V_{f}\right.$, blue) and the inlet area $\left(V_{i}\right.$, red), used to calibrate the morphodynamic model.

During model calibration, the morphological model was forced with a schematized tide [35], [45] based on the tidal asymmetry between the main diurnal (O1 and K1) and semidiurnal (M2) tidal components and with a morphological acceleration factor, MorFac, of 48. Because both areas are located within the lagoon, the wave effects on sediment transport were assumed negligible. The dominant sediment size found in the flood delta was $\mathrm{D}_{50}=425 \mu \mathrm{m}$ [46]. The sedimentation and erosion results for both areas $\left(V_{f}\right.$ and $\left.V_{i}\right)$ together with the long term measured data are presented on Table 3. The estimation for the latter morphological period (1978-2001) provides a better estimate since the flow regimes in the Faro-Olhão and Armona inlets are closer to the conditions described by the present bathymetry.

The model produced good quantitative results with accretion at the flood delta and erosion at the inlet channel, suggesting a good functioning of the model, able to reproduce the main morphological patterns in the vicinity to the inlet. Overall, model values compare favourably in terms of magnitude to the best estimates of accretion/erosion volume obtained by [33] for two different periods. After calibration the morphological simulation was repeated using a smaller 


\section{Pre-print}

morphological acceleration factor $(M o r F a c=12)$ and for various spring-neap tidal cycle. The results of this simulation were in good agreement with the model results obtained with larger MorFac values and schematized tidal forcing, suggesting a good and coherent representation of the sediment patterns by the model. Finally, a MorFac of 26 (equivalent to a period of $\sim 1$ year) was adopted for the numerical simulations used during array optimisation.

Table 3 - Accretion/erosion measured and model estimates for both flood delta and inlet channel polygons ( $V f$ and $V i$ ). Error bounds in [33] represent the propagated error associated with the measurement and digitisation uncertainty.

\begin{tabular}{|c|c|c|c|}
\hline & \multicolumn{2}{|c|}{ Flood Delta $V_{f}\left(\mathbf{m}^{3} \cdot\right.$ year $\left.^{-1}\right)$} & \multirow{2}{*}{$\begin{array}{l}\text { Inlet Channel } V_{i}\left(\mathrm{~m}^{3} \cdot \mathrm{year}^{-1}\right) \\
1962-1978\end{array}$} \\
\hline & 1962-1978 & 1978-2001 & \\
\hline Pacheco et al., 2008 & $(5.08 \pm 0.46) \times 10^{4}$ & $(5.72 \pm 1.43) \times 10^{4}$ & $\begin{array}{c}(-5.68 \\
\pm 0.57) \times 10^{4}\end{array}$ \\
\hline Delft3d Model & \multicolumn{2}{|c|}{$4.36 \times 10^{4}$} & \\
\hline
\end{tabular}

\subsubsection{Modelling tidal energy losses}

The impact of energy extraction on flow and sediment transport patterns can be simulated by enabling or adding an additional sink/source momentum term in the equations of conservation of momentum to parameterize the extra loss of energy generated by a TEC array in a subgrid-scale. In Delft3D-Flow, the extra loss of energy can be parameterised using a quadratic energy loss term given by:

$$
\begin{aligned}
& M_{x}=-\frac{C_{\text {loss }-u}}{\Delta x} u \sqrt{u^{2}+v^{2}} \\
& M_{y}=-\frac{C_{\text {loss }-v}}{\Delta y} v \sqrt{u^{2}+v^{2}}
\end{aligned}
$$

where $C_{\text {loss }}$ depicts the energy loss coefficient; $\Delta x, \Delta y$ are the cell widths in the $\mathrm{x}$ and $\mathrm{y}$ directions, respectively; and $u$ and $v$ the Easting and Northing velocity components. Following the procedure presented in [47], the extra loss of energy can be related with the drag force, $F_{D}$, exerted in the fluid flow by an array of $N$ TECs. $F_{D}$ is composed of two parts, one due to the support-structure drag, with cross-sectional area $A_{s}$, and another due to the power extraction of the turbines, with a rotor swept area of $A_{T}$ with diameter $D$, i.e:

$$
F_{D}=\frac{1}{2} \rho N\left(C_{s} A_{s}+C_{T} A_{T}\right) U_{i n}^{2}
$$

$\rho$ depicts sea water density $\left(1025 \mathrm{~kg} . \mathrm{m}^{-3}\right), C_{s}$ and $C_{T}$ stand for the drag coefficient of the structure, and thrust coefficient of the rotor, respectively, and $U_{\text {in }}$ is the incident flow velocity. Because $F_{D}$ has force units and the momentum source term $M_{x}$ has acceleration units, and to be able to relate both quantities, it is necessary to divide Eq. (2) by the control volume mass where the TEC is located, e.g. for the $\mathrm{x}$-direction:

$$
\frac{\rho N\left(C_{s} A_{s}+C_{T} A_{T}\right) u \sqrt{u^{2}+v^{2}}}{2 \rho \Delta x \Delta y H}=\frac{C_{\text {loss }-u}}{\Delta x} u \sqrt{u^{2}+v^{2}}
$$




\section{Pre-print}

where $H$ is the water column height of the control cell. Here, it is assumed that the incident flow velocity is similar to the flow velocity at the porous plate, which is a valid approximation for a 2DH model, and where the TECs modelled are small compared with the grid cell. In cases where the TEC is similar to the grid cell size, a correction for the $C_{T}$ is needed when it is expressed as a function of the flow velocity at the porous plate [48]. Solving for $C_{\text {loss }}$ gives:

$$
C_{\text {loss }-u}=\frac{N\left(C_{s} A_{s}+C_{T} A_{T}\right)}{2 \Delta y H}
$$

Overall, this approach is similar to those used by other authors, where slight differences may exist depending on how the sink/source term is incorporated in the model and the numerical method employed, i.e. finite difference (e.g. [49]), finite volume (e.g. [13]) and finite element (e.g. [50]). The main difficulty of the approach is to determine the precise value of the drag coefficient of the TEC (i.e. rotor and support-structure) that generates the appropriate head loss, (i.e. wake velocity deficit). For a review on modelling energy extraction in tidal flows refer to [51].

A 1:4 $4^{\text {th }}$ scale Evopod device (E35 hereafter) from Oceanflow Energy Ltd. is used for calculations. The E35 has a diameter of $4.5 \mathrm{~m}$ and its semi-submerged support platform has a length of $13 \mathrm{~m}$, beam of $4.5 \mathrm{~m}$, height of $8 \mathrm{~m}$, displacement of 13 tonnes, and a rated output of 35 $\mathrm{kW}$ (Table 4). E35 was already tested at Sanda Sound West Scotland at $22 \mathrm{~m}$ water depth [47], an area that resembles Ria Formosa in terms of tidal resource and environmental constraints (i.e. depth and current velocities).

Table 4 - Tidal Energy Converter Evopod ${ }^{\mathrm{TM}}$ E1 and E35 specifications.

\begin{tabular}{lcc}
\hline \multirow{2}{*}{ Parameter } & \multicolumn{2}{c}{ Values } \\
\cline { 2 - 3 } & E1 & E35 \\
\hline Rotor diameter, $D[\mathrm{~m}]$ & 1.5 & 4.5 \\
Length, $L[\mathrm{~m}]$ & 3.5 & 13 \\
Cut-in speed, $U_{c i}\left[\mathrm{~m}_{\mathrm{s}} \mathrm{s}^{-1}\right]$ & 0.7 & 0.7 \\
Rated flow speed, $U_{r}\left[\mathrm{~m}_{\mathrm{s}} \mathrm{-}^{-1}\right]$ & 1.75 & 2.3 \\
Rated power, $P_{r}[\mathrm{~kW}]$ & 1 & 35 \\
Power coefficient, $C_{P}[-]$ & 0.28 & 0.35 \\
Thrust coefficient, $C_{T}[-]$ & 0.40 & 0.40 \\
Swept area, $A_{T}\left[\mathrm{~m}^{2}\right]$ & 1.77 & 15.9 \\
Structure drag coefficient, $C_{S}[-]$ & 0.15 & 0.15 \\
TEC frontal area, $A_{S}\left[\mathrm{~m}^{2}\right]$ & 2.03 & 18.3 \\
\hline
\end{tabular}

Using mooring tension data from an Evopod 1:10 ${ }^{\text {th }}$ scale prototype deployment [52] and by fitting to the data a quadratic drag law of the form $y=\mathrm{A} x^{2}+\mathrm{b}$ with $y=F_{T, x}, \mathrm{~b}=F_{T, o}, x=U$; and $\mathrm{A}=0.5 \rho\left(C_{T} A_{T}+C_{s} A_{s}\right)$ an overall $C_{T}$ is obtained. Values given by the manufacturer for $C_{s}$ and $A_{s}$, are 0.15 and $2 \mathrm{~m}^{2}$, respectively, resulting in a $C_{T}=0.4$. In Fig. 5 , it is visible that a fix $C_{T}$ provides a good agreement with measurements. Finally, assuming a similar $C_{T}$ value for the E35 and by using Eq. (4), a $C_{\text {loss }}$ is calculated for each cell in the model where TECs are located. 


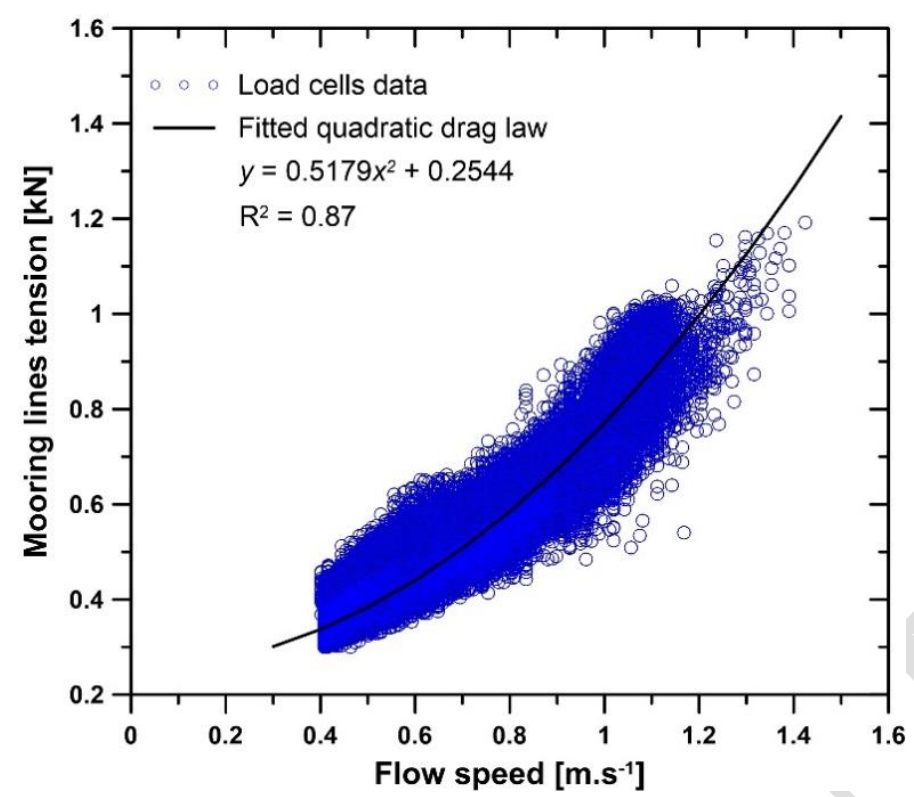

Fig. 5 - Mooring lines tension for the 1 kW Evopod deployed at Faro-Olhão Inlet, Ria Formosa. Those values correlated positively with the fitted quadratic drag law $\left(R^{2}=0.87\right)$.

\subsection{SBO Methodology}

\subsubsection{Problem formulation and design of computer experiments}

In order to formulate an optimisation model, it is necessary to define the objective function to maximise or minimise, the constraints and the design variables involved in the problem. The standard form of a mathematical optimisation model is defined by:

Maximise $\quad f_{0}(\mathbf{x})$;

Subject to: $\quad g_{i}(\mathbf{x}) \geq b_{i}, \quad i=1, \ldots, m ;$

$h_{j}(\mathbf{x})=d_{j}, \quad j=1, \ldots, k$

where the vector $\mathbf{x}\left\{x_{1}, \ldots, x_{s}\right\}$ depicts the set of design variables of the problem, the function $f_{0}$ : $\mathrm{R}^{\mathrm{n}} \rightarrow \mathrm{R}$ depicts the objective function, the functions $g_{i}$ and $h_{j}: \mathrm{R}^{\mathrm{n}} \rightarrow \mathrm{R}, i=1, \ldots, m$; and $j=1, \ldots, k$; depict the inequality and equality constraint functions, and the constants $b_{1}, \ldots, b_{m}$; and $d_{l}, \ldots, d_{k}$ provides bounds and values of the constraints. In surrogate-based optimisation, the validated surrogate can represent the objective function, i.e. $f_{0}(\mathbf{x})=\hat{y}(\mathbf{x})$, or any of the constraints, i.e. $g$ $(\mathbf{x})=\hat{g}(\mathbf{x})$. Furthermore, there are optimisation models formulated using multiple surrogates as is the case of the present study.

In the TEC array layout problem the design variables are up to the choice of the designer and specific for each case. Several options can be used as expressed in [24], [25]. For the purpose of this study, the TEC layout optimisation problem is formulated as function of two design variables $\mathbf{x}\left\{x_{1}, x_{2}\right\}$, the number of rows of the array $\left(x_{1}\right)$ and the number of devices in each row $\left(x_{2}\right)$ that maximises the capacity factor of the layout subject to a series of constraints.

Array row characteristics are defined based on the main features of the Faro-Olhão Inlet features (i.e. geometry and water depths), energy resource (i.e. occurrence of flow velocities) and TEC specifications (e.g. rotor diameter, length, etc). The tidal resource in the region is characterised using the validated hydro-morphodynamic model. Fig. 6 shows a contour map of 


\section{Pre-print}

the Faro-Olhão Inlet region with occurrence of tidal currents with velocities stronger than $0.7 \mathrm{~m} . \mathrm{s}^{-}$ ', which is the cut-in velocity for the E35 turbine. From the contour map, it is evident that the highest energy resource is at the inlet throat. As a result, the first TEC row is placed at the inlet throat and successive rows are placed inwards with a fixed streamwise spacing between rows of $20 D\left(D\right.$, rotor diameter) to allow a reasonable wake recovery, i.e. velocity deficit, $U / U_{o}, \leq 0.95$ [53]. Considering occurrence of tidal currents stronger than the turbine's cut-in velocity during $\sim 25 \%$ of the time or above, the maximum number of rows is set to 13 composing a maximum array length of $1135 \mathrm{~m}$. TEC rows are placed in regions with depths $\geq 10 \mathrm{~m}$, therefore array rows are not symmetrically aligned across the streamwise axis. Each TEC row has a width of $162 \mathrm{~m}$, which matches the width of the inlet throat. The number of E35 TECs in each row varies from 6 to 11 units, corresponding to a lateral spacing of $6 D$ and $3 D$, respectively plus $3 D$ of clearance at the tip of the rows. The maximum number of turbines in a row is defined in order to let the rotation of the devices align with the tidal currents, while the minimum number of devices is set to decrease blockage effects.
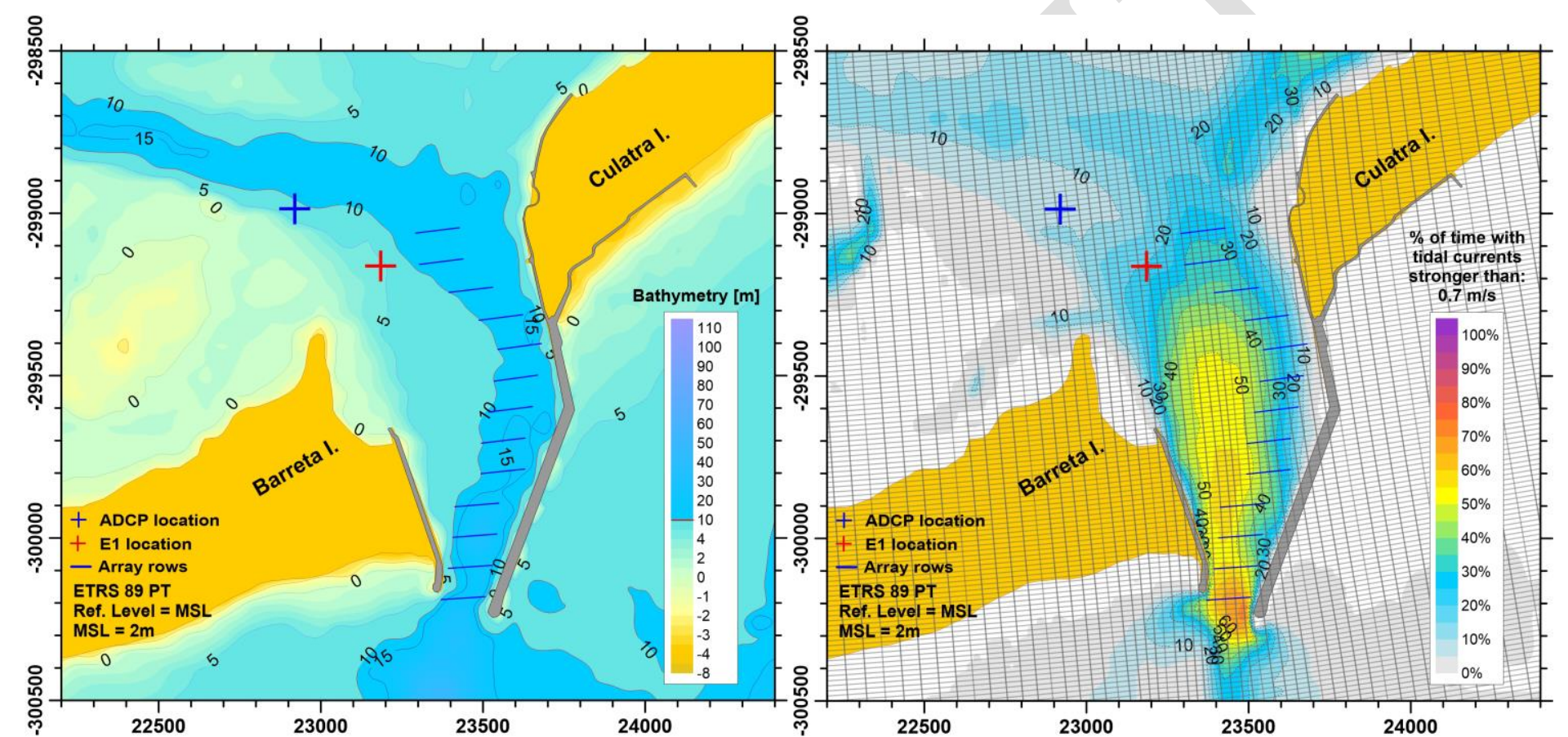

Fig. 6 - (Left) bathymetry contours and (Right) occurrence of tidal currents with velocities stronger

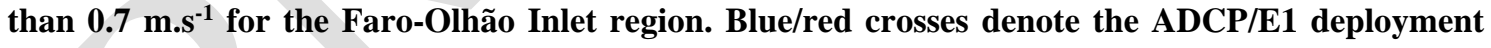
locations, the blue lines represent TEC rows and grey lines show the computational grid.

A series of constraints are included in the optimisation model to find the optimum installed capacity of a TEC array without creating significant detrimental environmental impacts on a regional level. The environmental aspects considered for analysis are related with tidal discharges and morphological processes that are detailed in sub-section 3.2.2. Thus, TEC array size, and its effects on flow characteristics and inlets morphology, are described through surrogates built as functions of two integer design variables: the number of rows in the array $\left(x_{1}\right)$ and the number of TECs for every row of the array $\left(x_{2}\right)$. The intervals of each integer variable are set to: $x_{1} \in[1,13]$ and $x_{2} \in[6,11]$.

Once the optimisation model is conceptually formulated, surrogates for the objective function and constraints have to be built. For this purpose, it is necessary to conduct a series of computer simulations to adequately describe the design space. The size of the sample plan should be around ten times the number of design variables as suggested in [54]. Fig. 7 illustrates the sample plan adopted in this study, which consists of 2 factors (i.e. design variables) with 6 and 


\section{Pre-print}

13 levels each, respectively, and with 15 sample points for each variable giving an experimental design plan size of 30 data points (blue dots). An additional 3 points (red dots) are added for surrogate validation.

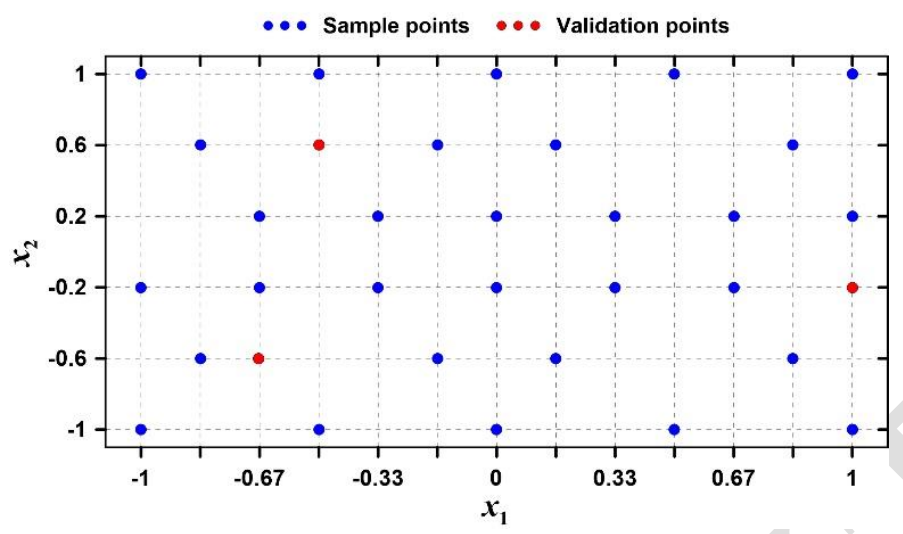

Fig. 7 - Normalised [-1 to 1] sample plan design. Blue points represent initial sampling plan and red dots represent validation points. Variables limits: $x_{1} \in[1,13]$ TECs and $x_{2} \in[6,11]$ rows.

\subsection{2. $\quad$ Numerical simulations}

The validated numerical model detailed in sub-section 3.1 is employed to execute the 30 cases defined in the sample plan and the 3 validation points shown in Fig. 7. Simulations are run for a fortnight cycle $\sim 14$ days, using a morphological time scale factor of 26 to quantify bed-level changes after a period of 364 days (i.e. 1 year). Here, the effect of wind is discarded. In Appendix A, Table A.1 to Table A.4 summarize the results obtained for the sample plan (cases 1 to 30) and validation points (cases 31 to 33). For each of the simulations the following outputs are obtained: (i) Capacity Factor of the array $\left(C F_{\text {Array }}\right)$ and of each TEC row within the array $\left(C F_{i}\right.$ for $i=1, \ldots, 13)$; (ii) percent differences of cumulative flood and ebb instantaneous discharges $\left(\Delta \Sigma Q_{i}\right)$ during a spring tide cycle at each tidal inlet and for the whole lagoon system; (iii) percent differences of the cumulative flood and ebb instantaneous discharges ratio between Armona and the Faro-Olhão inlets $\left(\Delta \Sigma Q_{A r} / \Delta \Sigma Q_{F O}\right)$; and (iv) net sediment volume changes $(\Delta V)$ and differences in average depth changes $\left(\Delta h_{\text {avg }}\right)$ for the Faro-Olhão Inlet flood delta and the Armona Inlet.

Due to the fact that the E35 is a floating device, capacity factors for each TEC row were calculated using a transformation of the depth averaged velocity, $\bar{U}$, obtained by the model simulations, into a flow velocity at rotor centreline, $U_{r}$, using a power law of the form:

$$
U_{r}=\bar{U}\left(\frac{z}{\beta H}\right)^{1 / \alpha}
$$

where $z$ is the depth of the rotor centreline, i.e. $4 \mathrm{~m}$ below water level; $\beta$ and $\alpha$ are the bed roughness and power law coefficients, with values of 0.4 and 7 , respectively. The values of these coefficients have been selected using ADCP data and their values have been maintained constant for the entire array. Then, capacity factors were calculated using Eq (6):

$$
C F_{i}\left(x_{1}, x_{2}\right)=\frac{\sum_{j}^{m} P_{i, j}}{\sum_{j}^{m} P_{r, i, j}}, \quad i=1, . ., n ; j=1, \ldots, m
$$




\section{Pre-print}

with $P_{i}$ and $P_{r, i}$ depicting the power output and the rated power of $i$-th array row at the $j$-th simulation time step, respectively. The analysis of percent differences of cumulative sedimentation/erosion net volume and average gain/loss of depth focuses on the Faro-Olhão and Armona inlets. This decision is based on the following premises: 1) there are no restrictions imposed on the morphological evolution of the Ancão Inlet; 2) near-field effects of TECs on morphodynamics (i.e. red polygon in Fig. 5) are considered not representative due to the numerical model limitations to solve flow-turbine interactions and approximations considered i.e. TECs are modelled as porous-plates in a sub-grid scale using a 2DH approach, where turbine diameter is much smaller than the grid cell size (for a full review of the limitations modelling TECs with Delft3D refer to [51]); and 3) morphodynamic results for Fuseta and Tavira are negligible based on the result of the numerical simulations (Table A.3). For Faro-Olhão and Armona inlets, the morphodynamic responses are computed in the area contained by the polygons defined in Fig. 4 (blue polygon) and Fig. 8, respectively. Both selected polygons represent the areas were expected morphological changes could be higher in association to changes on the hydrodynamic regime, based on the analysis performed by Pacheco et al. [33]. Furthermore, for the Faro-Olhão Inlet, the polygon represents the area used to validate the morphological model and incorporates some of the most valuable geomorphic features of the inlet. For the Armona Inlet, the area within the polygon also defines the navigational channel where cumulative sedimentation/erosion net volumes and depth changes have to be under control.

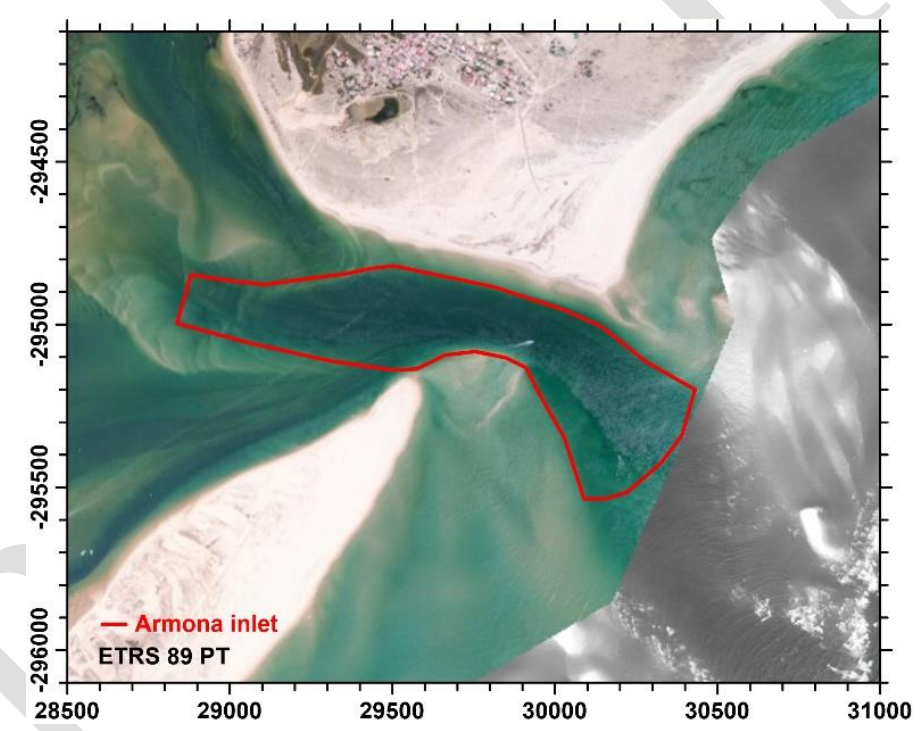

Fig. 8 - Aerial photo of Armona Inlet. Red line denotes the polygon within which sedimentation/erosion rates are calculated.

\subsubsection{Surrogate construction and validation}

After the simulations are executed generating the sample data, the surrogates are built. Regarding surrogate selection, there are multiple candidates, each with its advantages and limitations. In order to choose the right surrogate method, Santos [55] describes a series of criteria based on the characteristics of the problem. In the present work, the Radial Basis Function (RBF) method is used because it provides a predictor that passes through all given values of sample points, thus it can express highly non-linear responses. A RBF is a real valued function whose data points, $\mathrm{x}$, are affected on their distance, $r$, from another data point, $\mathrm{x}_{i}$, named a centre. The distance between the two points is represented by a norm, usually the Euclidian norm, $r=\left\|\mathrm{x}-\mathrm{x}_{i}\right\|$. In this manner, a data point in a data set will affect to a greater extent the nearer points than the faraway points, in such a way that $\phi\left(\mathrm{x}, \mathrm{x}_{i}\right)=\phi(r)=\phi\left(\left\|\mathrm{x}-\mathrm{x}_{i}\right\|\right)$. Thus, the manner in which the distance affects 


\section{Pre-print}

the data points depends on the basis function selected. In this study, the linear basis, $\phi(r)=r$, function is used. For more information on RBF see [56].

Therefore, an approximation response function, $\hat{y}_{i}$, may be constructed with the form:

$$
\hat{y}_{j}=\mathbf{w}^{\mathbf{T}} \phi=\sum_{i, j=1}^{n} w_{i} \phi\left(\left\|\mathbf{x}_{j}-\mathbf{x}_{i}\right\|\right), \quad i, j=1,2, \ldots, n
$$

where $\mathbf{w}$ is a vector containing the weights, $w_{i}$, for the linear combination of basis vectors contained in the vector $\phi$ with size $n$; which leads to the expression,

$$
\mathbf{y}=\mathbf{w}^{\mathrm{T}} \boldsymbol{\Phi}
$$

where $\mathrm{y}$ depicts the vector with the computer model responses and $\Phi$ is the matrix enclosing the linear combination of basis vectors.

The values of the weights are estimated using the least squares estimator presented in Eq. (9)

$$
\hat{\mathbf{w}}=\left(\boldsymbol{\Phi}^{\mathrm{T}} \boldsymbol{\Phi}\right)^{-1} \boldsymbol{\Phi}^{\mathrm{T}} \mathbf{Y}
$$

In this particular study, a total of 26 surrogates are built (i.e. $\hat{y}_{i}$ for $i=1, \ldots, 26$ ). While the first surrogate, $\hat{y}_{i}$ for $i=1$, depicts the capacity factor of the whole array, surrogates 2 to 14 , $\hat{y}_{i}$ for $i=2, . ., 14$, refer to the capacity factor of each array row. Differences in instantaneous cumulative discharges for flood and ebb spring tides of the Faro-Olhão and Armona inlets, the ratio between both (i.e. Armona/Faro-Olhão inlets), and the sum of all inlets are defined by surrogates 15 to $22, \hat{y}_{i}$ for $i=15, . ., 22$. Finally, surrogates 23 to $26, \hat{y}_{i}$ for $i=23, . ., 26$, represent the net volume and average bottom depth changes for the Faro-Olhão flood delta and Armona Inlet, respectively.

In order to select the most appropriate basis, each surrogate has to be assessed and validated. The assessment and validation of the surrogate consist in verifying its capacity to predict responses with data points not considered during the regression. For this purpose, a set of three $(p=3)$ testing points, $n_{p}$, illustrated in Fig. 7 , has been selected arbitrarily to carry out a leave- $p$ out cross validation error method [26],

$$
\varepsilon_{c v}=\frac{1}{n_{p}} \sum_{i=1}^{n_{p}}\left(y_{i}-\hat{y}_{i}\right)^{2} \quad n_{p} \in N
$$

To compute the leave- $p$-out cross validation error, the set of data points $N=n+n_{p}$, is divided into $q=N$ subsets of $n=30$ sample points. For each subset, the testing points not considered in the regression are predicted with the surrogate built using the remaining sample points. The leave$p$-out method enables to take advantage of the whole set of data points to construct the surrogate model employing the optimal subset of points that minimises the overall error of the model.

The Normalised Root Mean Square Error (NRMSE) and the Normalised Maximum Error (NMAXE) defined by Eqs (12) and (14), are used respectively, to study surrogate's performance. Forrester et al. [26] suggests that values of a NRMSE $<0.1$ and NRMSE $<0.02$ imply surrogates with reasonable and excellent predictive capabilities, respectively; i.e. 


$$
\begin{aligned}
& \mathrm{RMSE}=\left[\frac{1}{n_{p}} \sum_{i=1}^{n_{p}}\left(y_{i}-\hat{y}_{i}\right)^{2}\right]^{1 / 2} \\
& \mathrm{NRMSE}=\frac{\mathrm{RMSE}}{y_{\max }-y_{\min }} \\
& \mathrm{MAXE}=\max \left|y_{i}-\hat{y}_{i}\right| \\
& \mathrm{NMAXE}=\frac{\max \left|y_{i}-\hat{y}_{i}\right|}{y_{\max }-y_{\min }}
\end{aligned}
$$

Fig. 9 presents the NRMSE and NMAXE results for each of the 26 surrogates built using the technique of cross validation. For all surrogates, NRMSE and NMAXE results are below 0.02. Then, the set of surrogates are used for searching the unexplored design variables space.
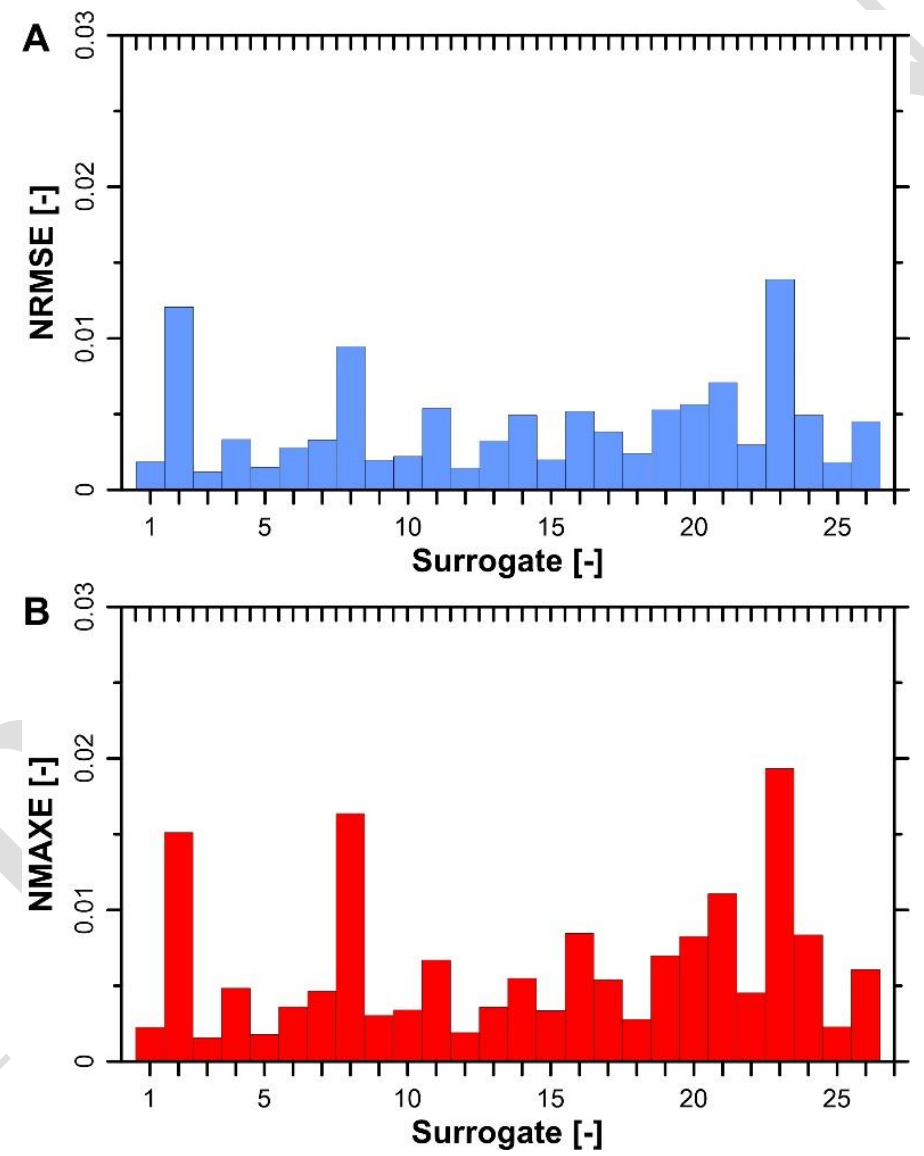

Fig. 9 - A) Normalised Root Mean Square Error (NRMSE) and B) Normalised Maximum Error (NMAXE) of surrogates after cross validation.

\subsubsection{Optimisation models}

Once the surrogates are built, they can be incorporated into the optimisation model representing the objective function and the constraints. Several examples are presented below to illustrate how surrogates can be used in the formulation of an optimisation model to define the size of a TEC array installed in a tidal channel subject to a set of constraints. Depending on the needs and the characteristics of the project, the objective function and constraints can be modified accordingly. Within this study, the values defined for the set of constraints relating array performance and 
environmental aspects are presented in Table 5 to Table 7. For instance the $C F$ values refer to the minimum acceptable $C F$ value to consider an array effective. For the discharges the values represent the maximum acceptable discharge change for each inlet and overall system. For the morphological aspects values refer to the maximum accepted changes in volume or vertical shifts at each inlet.

Table 5 - Values of the constraints related with performance aspects of the whole array, $C F_{A r r a y}$, and of each individual array row, $C F_{i}$.

\begin{tabular}{lcccccccccccccc}
\hline Constraint $\mathbf{N}^{\mathbf{0}}$ & $\mathbf{1}$ & $\mathbf{2}$ & $\mathbf{3}$ & $\mathbf{4}$ & $\mathbf{5}$ & $\mathbf{6}$ & $\mathbf{7}$ & $\mathbf{8}$ & $\mathbf{9}$ & $\mathbf{1 0}$ & $\mathbf{1 1}$ & $\mathbf{1 2}$ & $\mathbf{1 3}$ & $\mathbf{1 4}$ \\
\hline \multirow{2}{*}{ Constraint } & $\boldsymbol{C F}_{\text {Array }}$ & $\boldsymbol{C F}_{1}$ & $\boldsymbol{C F _ { 2 }}$ & $\boldsymbol{C F}$ & $\boldsymbol{C F}$ & $\boldsymbol{C F}$ & $\boldsymbol{C F}$ & $\boldsymbol{C F} 7$ & $\boldsymbol{C F}$ & $\boldsymbol{C F} 9$ & $\boldsymbol{C F}_{10}$ & $\boldsymbol{C F}_{11}$ & $\boldsymbol{C F}_{12}$ & $\boldsymbol{C F}_{13}$ \\
& {$[\%]$} & {$[\%]$} & {$[\%]$} & {$[\%]$} & {$[\%]$} & {$[\%]$} & {$[\%]$} & {$[\%]$} & {$[\%]$} & {$[\%]$} & {$[\%]$} & {$[\%]$} & {$[\%]$} & {$[\%]$} \\
\hline Value & 12.5 & 15 & 12 & 10 & 10 & 10 & 10 & 10 & 10 & 10 & 10 & 10 & 10 & 10 \\
\hline
\end{tabular}

Table 6 - Values of the environmental constraints related with flood/ebb spring discharges $(\Delta \Sigma Q)$ for Faro-Olhão ( $F o$ ) and Armona $\left({ }_{A r}\right)$ inlets, and their discharges ratio $\left(\Sigma Q_{A r} / \Sigma Q_{F o}\right)$. Subscripts $f$ and $e$ depict for flood and ebb tides, respectively.

\begin{tabular}{lcccccccc}
\hline Constraint $\mathbf{N}^{\mathbf{0}}$ & $\mathbf{1 5}$ & $\mathbf{1 6}$ & $\mathbf{1 7}$ & $\mathbf{1 8}$ & $\mathbf{1 9}$ & $\mathbf{2 0}$ & $\mathbf{2 1}$ & $\mathbf{2 2}$ \\
\hline \multirow{2}{*}{ Constraint } & $\Delta \Sigma Q_{f, F O}$ & $\Delta \Sigma Q_{f, A r}$ & $\Sigma Q_{f, A r} / \Sigma Q_{f, F O}$ & $\Delta \Sigma Q_{f, \text { all }}$ & $\Delta \Sigma Q_{e, F O}$ & $\Delta \Sigma Q_{e, A r}$ & $\Sigma Q_{e, A r} / \Sigma Q_{e, F O}$ & $\Delta \Sigma Q_{e, \text { all }}$ \\
& {$[\%]$} & {$[\%]$} & {$[\%]$} & {$[\%]$} & {$[\%]$} & {$[\%]$} & {$[\%]$} & {$[\%]$} \\
\hline Value & -10 & 10 & 7.5 & -5 & -5 & 2.5 & 2.5 & -2.5 \\
\hline
\end{tabular}

Table 7 - Values of the environmental constraints related with morphological aspects. $\Delta V_{\text {net }}$ and $\Delta h_{\text {avg }}$ stand for the net sediment volume and average depth differences, respectively, for Faro-Olhão ( $\mathrm{Fo}$ ) and Armona $(A r)$ inlets.

\begin{tabular}{|c|c|c|c|c|}
\hline Constraint $\mathbf{N}^{\circ}$ & 23 & 24 & 25 & 26 \\
\hline Constraint & $\Delta V_{n e t, F O}\left[\mathbf{m}^{3} / \mathbf{y r}\right]$ & $\Delta V_{n e t, A r}\left[\mathbf{m}^{3} / \mathbf{y r}\right]$ & $\Delta \boldsymbol{h}_{\text {avg, } \mathrm{FO}}[\mathrm{cm} / \mathrm{yr}]$ & $\Delta h_{\text {avg }, A r}[\mathrm{~cm} / \mathrm{yr}]$ \\
\hline Value & $-10,000$ & 40,000 & -5 & 15 \\
\hline
\end{tabular}

\section{Model 1}

The objective of the first model consists in defining the maximum number of array rows, $x_{1}$, that can be installed without affecting the environment adversely. These effects are quantified by a set of constraints inequalities, $\hat{\mathbf{g}}(\mathbf{x}) \leq \mathbf{b}$, where $\hat{\mathbf{g}}(\mathbf{x})$ depicts a set of the built surrogates representing the environmental responses (i.e. cumulative discharges, net sedimentation/erosion volumes, etc.), $\mathbf{b}$ is a vector containing the values of the restrictions imposed and $\mathbf{x}$ is the set of design variables. Notice that each row has associated 6 possible TECs combinations, i.e. for $x_{2} \in$ $\{6, \ldots, 11\}$, which could yield more than one optimum solution. Therefore, in order to avoid a multiple solution problem, it is necessary to include an additional objective function to be maximised or minimised. This could be, for example, maximise power output or array capacity factor, or even minimise any particular environmental impact. For the purpose of this study, the capacity factor is selected as the second objective function to be maximised, which is again used in models 2 and 3 .

Then, the mathematical formulation of the multi-objective optimisation problem is as follows:

Maximise $\left\{x_{1}, C F_{\text {Array }}(\mathbf{x})\right\}$ 


\section{Pre-print}

Subject to:

$$
\begin{aligned}
& \hat{g}_{i}(\mathbf{x}) \geq b_{i}, \quad \forall i \in\{15,18,19,22,23,25\} \\
& \hat{g}_{i}(\mathbf{x}) \leq b_{i}, \quad \forall i \in\{16,17,20,21,24,26\} \\
& x_{1} \in\{1, . ., 13\}, x_{2} \in\{6, \ldots, 11\}
\end{aligned}
$$

\section{Model 2}

Similarly to Model 1, there is the possibility to maximise the number of TECs per row, $x_{2}$, that will not violate the environmental restrictions imposed. This way, the mathematical formulation of Model 2 is as follows:

Maximise $\left\{x_{2}, C F_{\text {Array }}(\mathbf{x})\right\}$

Subject to:

$$
\begin{aligned}
& \hat{g}_{i}(\mathbf{x}) \geq b_{i}, \quad \forall i \in\{15,18,19,22,23,25\} \\
& \hat{g}_{i}(\mathbf{x}) \leq b_{i}, \quad \forall i \in\{16,17,20,21,24,26\} \\
& x_{1} \in\{1, . ., 13\}, x_{2} \in\{6, \ldots, 11\}
\end{aligned}
$$

\section{Model 3}

Alternatively to models 1 and 2, the problem can be formulated in terms of finding the maximum number of TECs, i.e. $x_{1} x_{2}$, that the system could handle without violating the environmental constraints:

Maximise $\left\{x_{1} x_{2}, C F_{\text {Array }}(\mathbf{x})\right\}$

Subject to:

$$
\begin{array}{ll}
\hat{g}_{i}(\mathbf{x}) \geq b_{i}, & \forall i \in\{15,18,19,22,23,25\} \\
\hat{g}_{i}(\mathbf{x}) \leq b_{i}, & \forall i \in\{16,17,20,21,24,26\} \\
x_{1} \in\{1, . ., 13\}, x_{2} \in\{6, \ldots, 11\}
\end{array}
$$

\section{Model 4}

As models 1 to 3 do not ensure an overall efficient array, there is the possibility to formulate the model in terms of maximising the number of TECs and the total power output of the array but imposing minimum values of efficiency for the whole array as well as for each individual row.

Maximise $\left\{x_{1} x_{2}, P_{\text {Array }}\right\}$

Subject to:

$$
\begin{array}{ll}
P_{\text {Array }}=C F_{\text {Array }}(\mathbf{x}) & x_{1} x_{2} P_{r} t \\
\hat{g}_{i}(\mathbf{x}) \geq b_{i}, & \forall i \in\left\{1, \ldots, x_{2}+1\right\} \\
\hat{g}_{i}(\mathbf{x}) \geq b_{i}, & \forall i \in\{15,18,19,22,23,25\}
\end{array}
$$




$$
\begin{aligned}
& \hat{g}_{i}(\mathbf{x}) \leq b_{i}, \quad \forall i \in\{16,17,20,21,24,26\} \\
& x_{1} \in\{1, . ., 13\}, x_{2} \in\{6, \ldots, 11\}
\end{aligned}
$$

Equations (15), (19), (23) and (27) define the objective functions to be maximized. In Model 4, $P_{r}$ stands for the rated power of the turbine $(35 \mathrm{~kW})$, and the time interval to compute power production (364 days.yr-1 ${ }^{-1}$. Equations (16), (17), (20), (21), (24), (25), (30) and (31) establish the set of environmental constraints, i.e. the $\mathrm{min} / \mathrm{max}$ values of the constraints presented in Table 5 to Table 7; while equation (29) designates the set of performance constraints related with minimum allowable capacity factors for the array, and for each row. Equation (28) defines how to calculate the overall power output of the array. Finally, equations (18), (22), (26) and (32) declare the values of the integers variables, i.e. the number of rows and the number of TECs per row. The value of the variable indicating the number of rows implicitly considers which array rows are turned on and off, due to the fact that array rows are placed consecutively with respect to the first row, which is always placed at the inlet throat.

\section{Design space exploration and optimisation model results}

\subsection{Design space exploration}

The design variables space are explored through the built surrogates. Responses of each surrogate within the design variables domain are presented graphically in Fig. 10 to Fig. 15. While the Fig. 10 presents the annual power output for all possible TEC arrays, Fig. 11 illustrates the capacity factors for the TEC array as well as for each array row. Outputs are obtained evaluating the surrogates in all possible combinations of the two design variables (i.e. 78 array layouts). From these figures, it is clear that although larger arrays yield higher power outputs, the overall efficiencies are very low. On the other hand, the first rows of the potential arrays (i.e. the one located at the inlet throat) benefit from faster flows yielding higher power outputs than rows positioned further inside the lagoon, where the available tidal resource is lower.

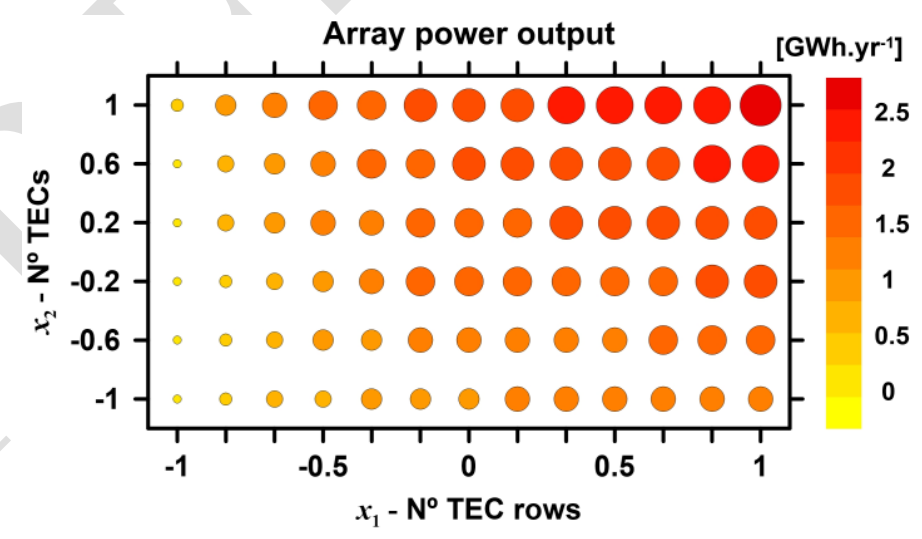

Fig. 10 - Classed post plot presenting array annual power output results for all possible combinations of the two design variables (i.e. 78 array layouts). The plots show that the highest power output is achieved by larger size arrays i.e. with 13 rows and 11 TECs/row. Variables limits are: $x_{1} \in[1,13]$ rows and $x_{2} \in[6,11]$ TECs per row. 


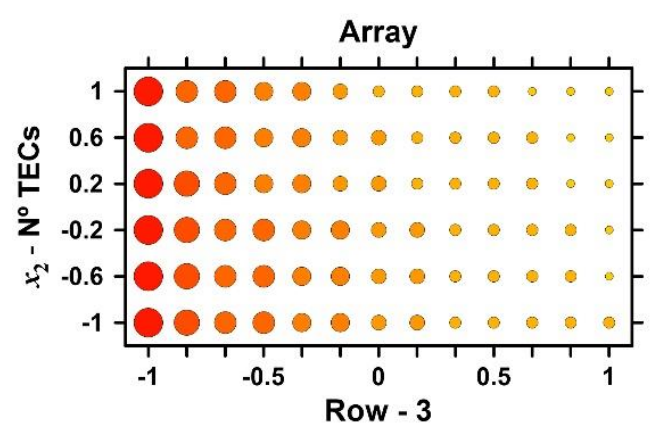

Row - 1
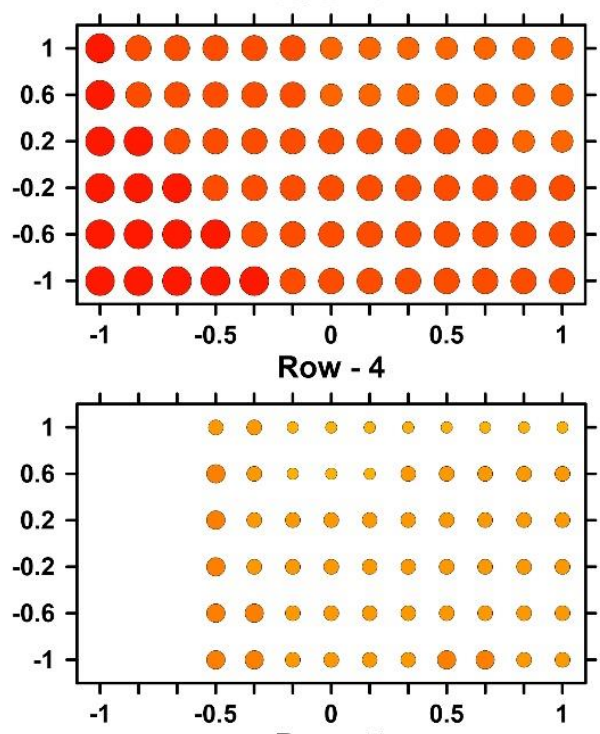

Row - 7
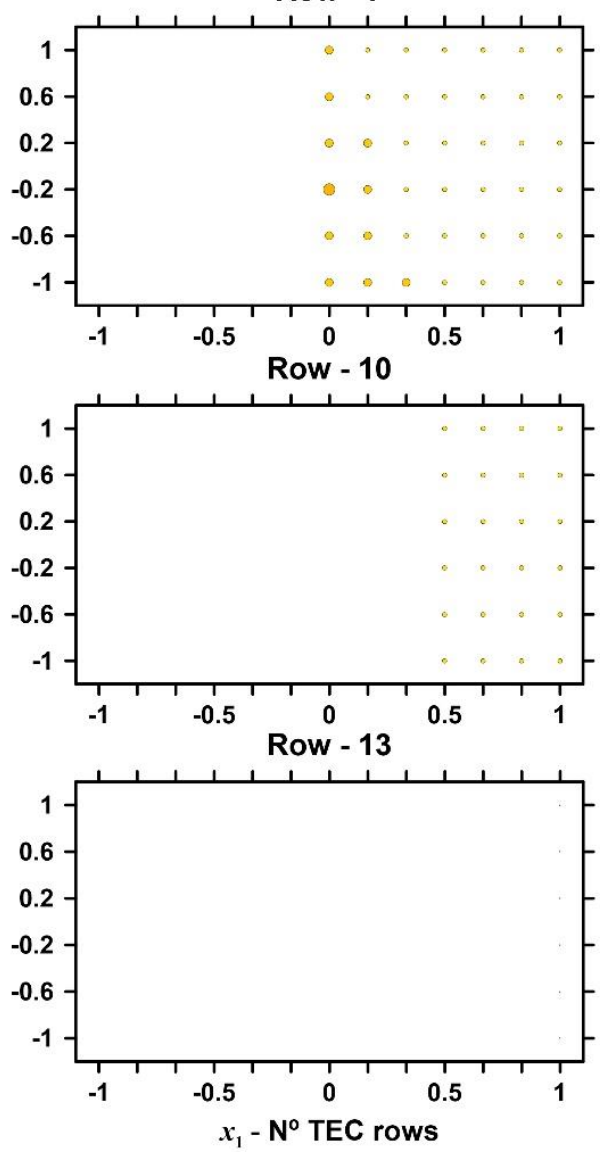

Row - 2
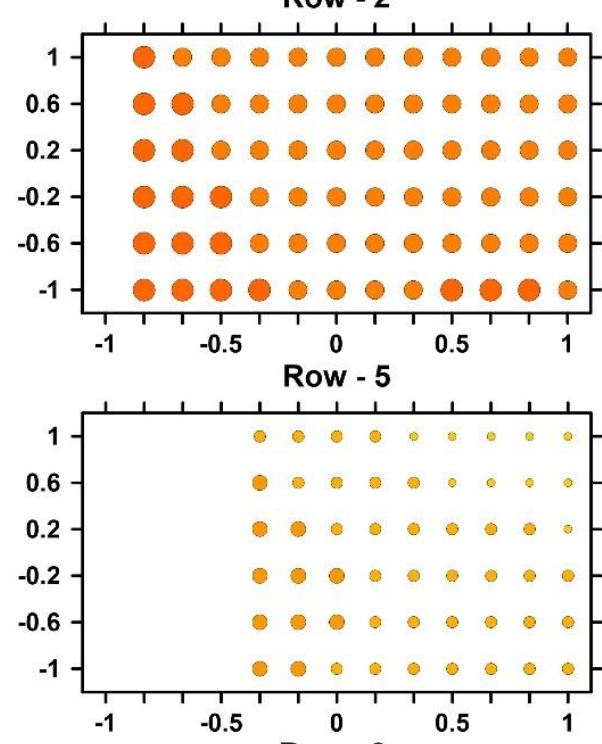

Row - 8
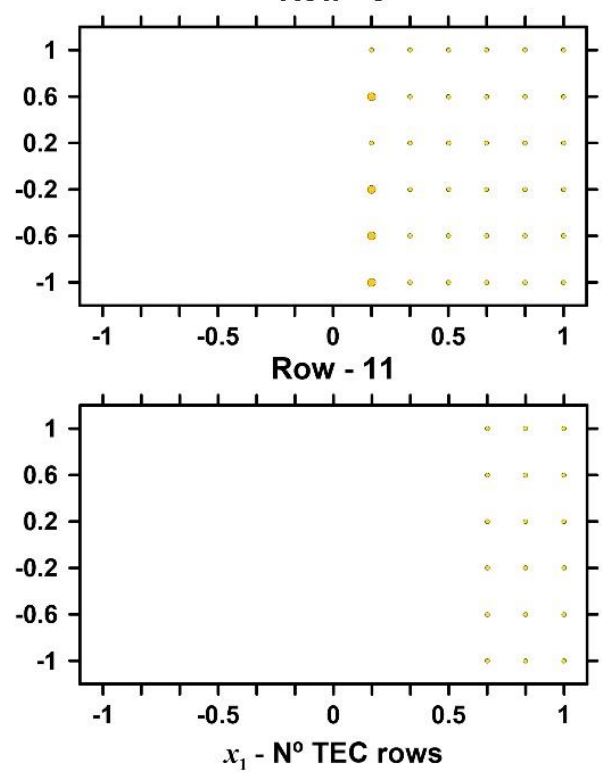

Capacity Factor [\%]

$\begin{array}{llllllllllll}0 & 2 & 4 & 6 & 8 & 10 & 12 & 14 & 16 & 18 & 20\end{array}$

Fig. 11 - Classed post plot presenting capacity factor results of all possible combinations of the two design variables (i.e. 78 array layouts) for the whole array (top left corner) and for each row (row 1 to 13). The plots show that the highest capacity factors are achieved by arrays with few rows $\left(x_{1} \leq 5\right)$. The effect of the number TECs $\left(x_{2}\right)$ varies within each row an in all rows, e.g. in the plot for Row-3, capacity factors are visible larger for cases with 7-9 TECs than for case with 6, 10 and 11 TECs. Variables limits are: $x_{1} \in[1,13]$ rows and $x_{2} \in[6,11]$ TECs per row.

The power outputs generated and the capacity factors achieved by the set of TECs and rows that form each one of the possible array layouts are plotted in Fig. 12. From this figure, it is visible how power output and capacity factors achieved by the array tend to reach an asymptotic behaviour with increasing turbine number. This behaviour implies that by adding more TECs will 


\section{Pre-print}

not result in substantial gains on array power production, which is specifically true for arrays size $\geq 120$ devices. Moreover, array capacity factor decreases by increasing the number of TECs until it reaches a constant value of around 6\%. In Fig. 12A, it is noticeable that the largest variability on power output and capacity factor occurs for arrays with a number of TECs between 36 and 117 units, and between 30 and 90 units, respectively. On the other hand, in Fig. 12B, differences in array power output increase with array size, with values that go from $0.24 \mathrm{GWh}_{\text {.year }}{ }^{-1}$ to 0.79 GWh.year ${ }^{-1}$ for arrays with 1 and 13 rows, respectively. This implies that depending on the array configuration, power outputs can vary significantly for arrays with the same number of TECs. The largest difference $\left(\sim 0.4 \mathrm{GWh}_{\text {.year }}{ }^{-1}\right)$ is obtained for an array with 66 TECs, where the array configuration of 6 rows with 11 TECs per row has better performance that an array with 11 rows and 6 devices per row. Regarding array capacity factor, variability for arrays with same number of rows are not so large and stay within $1 \%$ and $1.4 \%$. The largest fluctuations are observed for arrays with 1 row and for mid-size arrays, i.e. arrays with 6 to 7 rows. For arrays with 7 rows, array capacity factors do not always decrease with increasing the number of TECs per row. For this case, the highest capacity factor is obtained when 8 TECs are placed in each row.
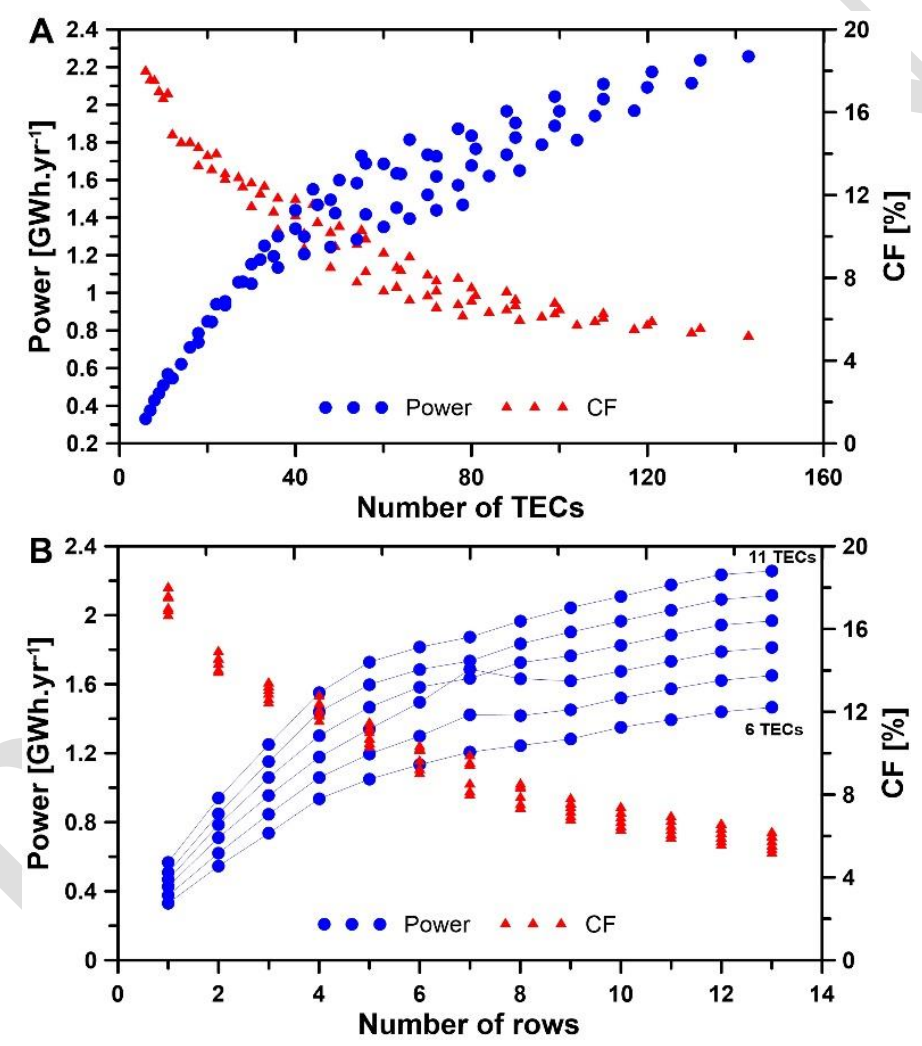

Fig. 12 - Array annual power output and capacity factor as a function of both design variables: A) number of TECs, and B) number of rows.

Fig. 13 illustrates these phenomena showing the variability of the tidal resource in terms of power density without TECs and for two array configurations of 13 rows and, 6 and 11 devices, respectively. As can be seen from Fig. 13, the tidal resource varies in each row and decreases further away from the inlet throat, although not linearly. In general, for the two cases presented, the capacity factor is lower for the case with more devices; however the differences between both cases are not proportional in each row. 


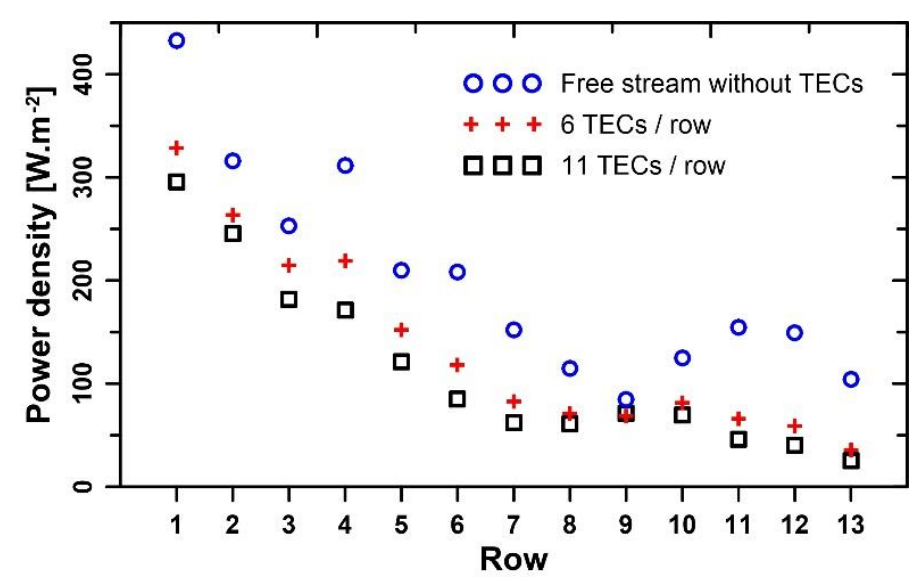

Fig. 13 - Power densities for each row of a 13 row array with 6 (red crosses) and 11 (black squares) TECs. Blue circles depict the available power densities without the presence of TECs.

The environmental implications on flood/ebb discharges are proportional to the number of TECs. Fig. 14 summarizes these results, by presenting differences of instantaneous cumulative discharges (A and B) and discharge ratios (C) for the Faro-Olhão and Armona inlets, and differences of instantaneous cumulative discharges (D) for all inlets, each of them assessed during flood (right) and ebb (left) tides. As the number of TECs increase, so do their impacts on discharges, which is greater on flood discharges than on ebb discharges. A reduction of the flood instantaneous cumulative discharges for all inlets will decrease the tidal prism of the lagoon, which in turn can influence water levels and water quality inside the lagoon. In regard to sedimentation/erosion system response to array size, the Faro-Olhão and the Armona inlets present different responses. While for the Faro-Olhão Inlet there is a more clear effect of the number of rows on morphological changes, the Armona Inlet is more sensitive to both design variables, i.e. intensify with increasing number of turbines. Sedimentation rates at Faro-Olhão flood delta (Fig. 15, left) decrease with array size, therefore net volume changes, $\Delta V_{\text {net, FO }}$, and average, $\Delta h_{\text {avg, } F O}$ depth bottom changes quantities are negative. This may result as a consequence of the sediment deposition in the Faro-Olhão Inlet (red polygon in Fig. 4) before reaching the actual flood delta (blue polygon in Fig. 4). The decrease of sedimentation rates at the Faro-Olhão delta may affect shellfish activities. Regarding the Armona Inlet (Fig. 15A, right), net volumes, $\Delta V_{n e t, A r}$, follow a similar trend to the tidal discharges i.e. erosion rates increase (positive values) with larger arrays. Similar patterns are observed for average bottom depths, $\Delta h_{\text {avg, }}{ }_{A}$, (Fig. 15B, right) being larger with arrays of more TECs. Larger erosion rates at the Armona Inlet will generate larger deposition volumes at the flood and ebb tidal deltas, which consequently can have effects, for example, in waterways and shellfish regions. In conclusion, due to the hydrodynamic interconnectivity of Ria Formosa lagoon inlets, any changes in the morphology of one inlet, due to changes of water circulation patterns, will impact the adjacent ones [57]. Therefore, any major change will disrupt this fragile equilibrium and alter the Ria Formosa physiography, with implications to all the social and economic activities. 
A F-O inlet, $\Sigma I Q$ spring flood tide

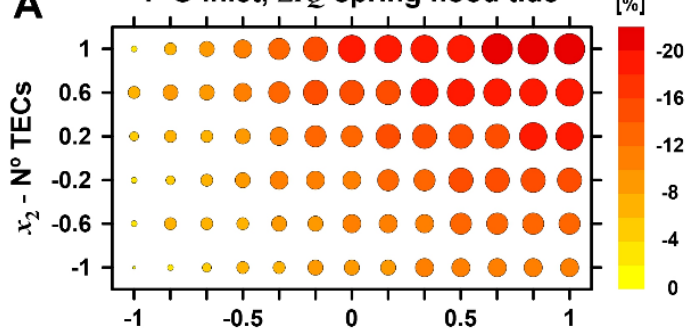

B

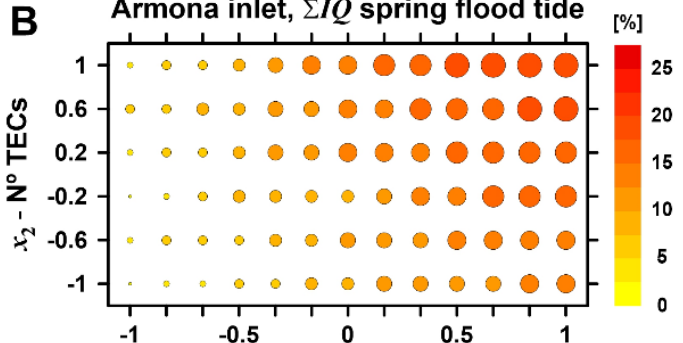

C Armona/F-O, $\Sigma I Q$ spring flood tide

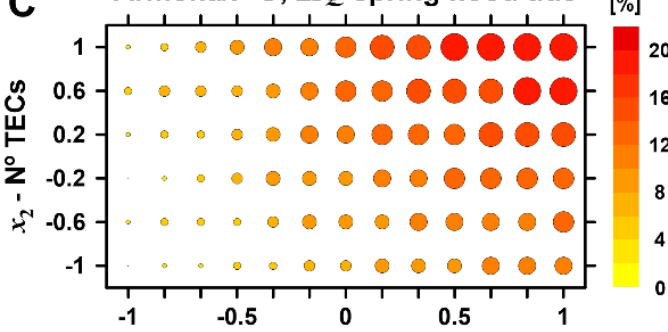

D All inlets, $\Sigma I Q$ spring flood tide

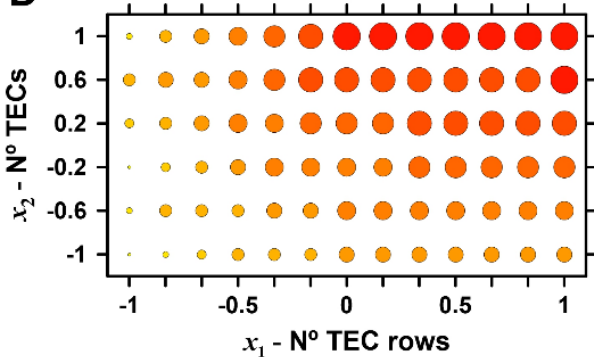

[\%]
F-O inlet, $\Sigma I O$ spring ebb tide

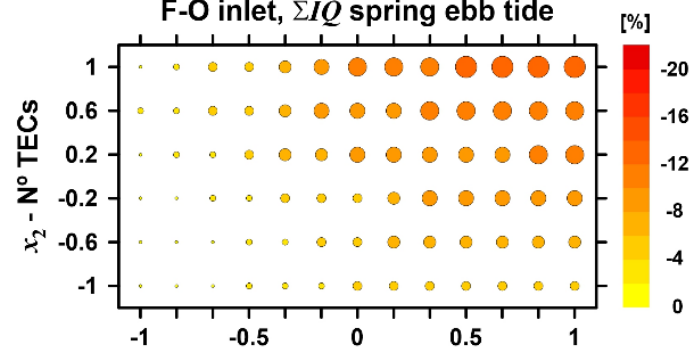

Armona inlet, $\Sigma I Q$ spring ebb tide

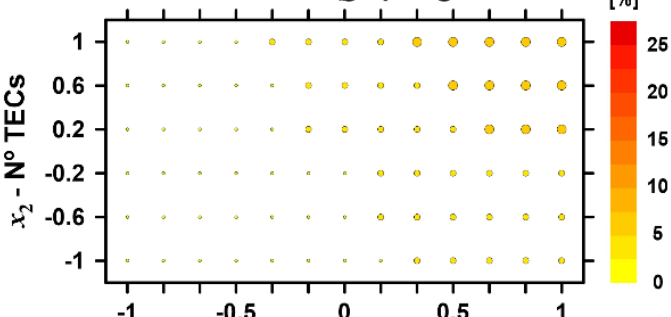

Armona/F-O, $\Sigma I Q$ spring ebb tide

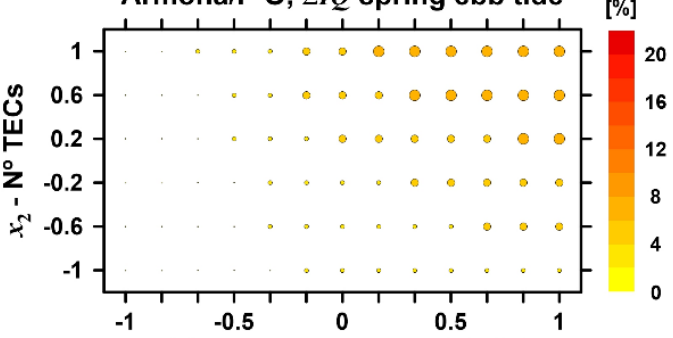

All inlets, $\Sigma I Q$ spring ebb tide

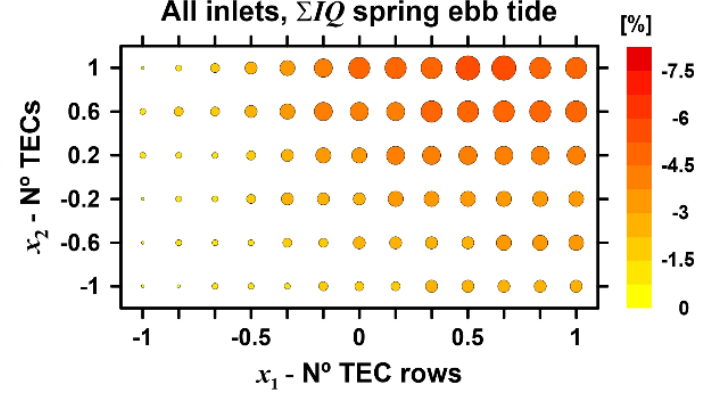

Fig. 14 - Classed post plot presenting: differences of instantaneous cumulative discharges (A and B) and discharge ratios (C) for the Faro-Olhão and Armona inlets, and differences of instantaneous cumulative discharges (D) for all inlets during flood (right) and ebb (left). Results are for all possible combinations of the two design variables (i.e. 78 array layouts). The baseline Armona/Faro-Olhão ratio for flood and ebb discharges are $37.8 \%$ and $35.8 \%$, respectively. Variables limits are: $x_{1} \in[1$, 13] rows and $x_{2} \in[6,11]$ TECs per row. 


\section{Pre-print}
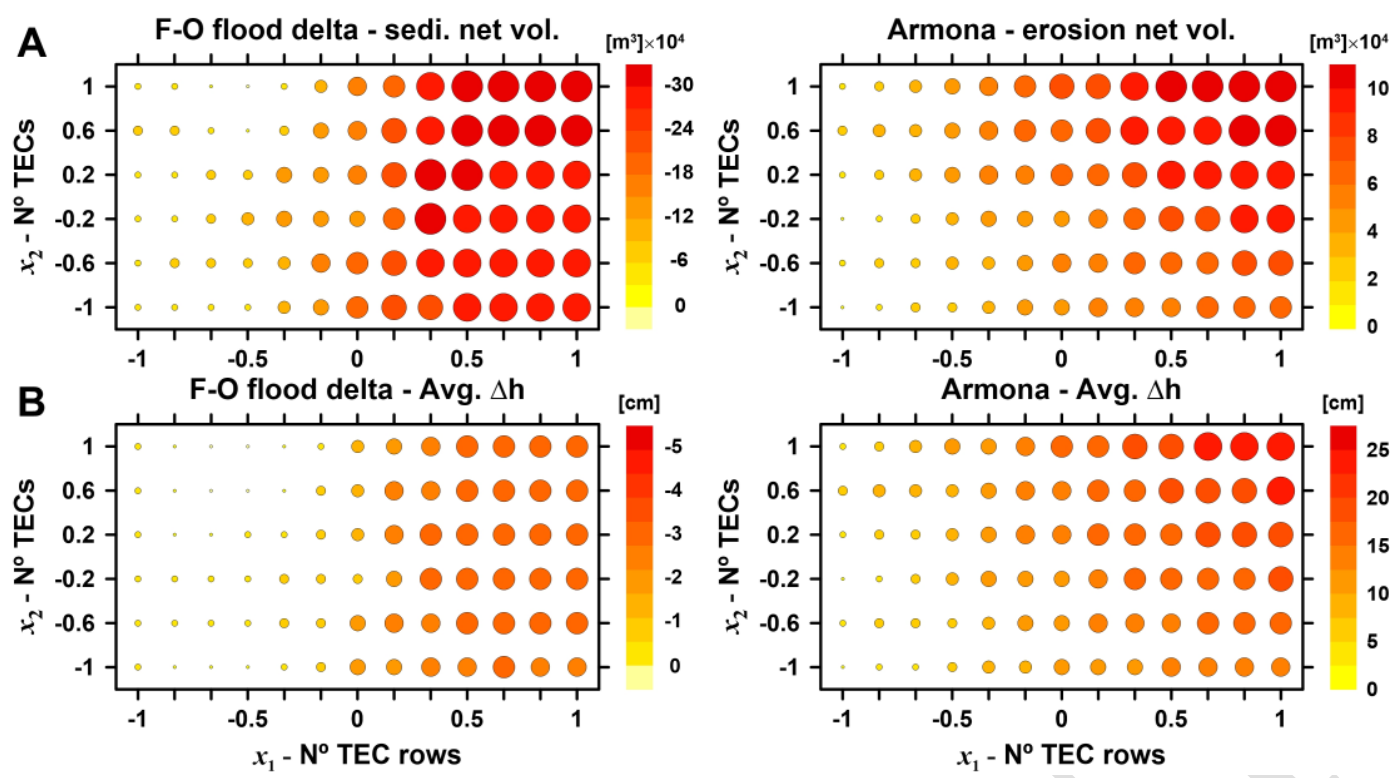

Fig. 15 - Classed post plot presenting: A) sedimentation/erosion net volume differences and B) average depth changes for the Faro-Olhão flood delta (left) and Armona inlet (right). Results are for all possible combinations of the two design variables (i.e. 78 array layouts. Positive and negative values indicate increase and decrease of scalar quantities, respectively. While the Faro-Olhão flood delta experiences sedimentation, the Armona Inlet erosion. Variables limits are: $x_{1} \in[1,13]$ rows and $x_{2} \in[6,11]$ TECs.

\subsection{Optimisation models results}

Solving the expressed models (Section 3.2.4), optimum solutions are obtained in compliance with the constraints imposed. Optimisation models are solved employing the enumeration method [58], which evaluates all possible combinations of the discretised design variables space. For each of the optimisation models, Table 8 shows the type of constraints considered (i.e. environmental and performance constraints), the value of the objective function (i.e. the optimum solution), the value of the design variables, the total number of TECs, the capacity factor of the array and its associated power output, while Table 9 to Table 11 present the values obtained for the sets of constraints.

Table 8 - Optimum solutions for each model. Results present the values for both design variables, objective function, capacity factor, $C F_{\text {Array }}$, and power output, $P_{\text {Array }}$, of the array. Constraints are classified as environmental (Envi.) and performance (Perf.)

\begin{tabular}{lccccccc}
\hline Model & $\begin{array}{c}\text { Constraints } \\
\text { considered }\end{array}$ & $\boldsymbol{x}_{\mathbf{1}}$ [rows] & $\begin{array}{c}\boldsymbol{x}_{\mathbf{2}} \\
{[\text { [TECs/row] }}\end{array}$ & $\begin{array}{c}\mathbf{N}^{\mathbf{0}} \\
\text { TECs }\end{array}$ & $\begin{array}{c}\text { Objective } \\
\text { function }\end{array}$ & $\begin{array}{c}\boldsymbol{C F}_{\text {Array }} \\
{[\%]}\end{array}$ & $\begin{array}{c}\boldsymbol{P}_{\text {Array }} \\
{\left[\mathbf{G W h}_{\mathbf{H}} \mathbf{- 1}\right]}\end{array}$ \\
\hline 1 & Env. & 5 & 6 & 30 & 5 & 11.4 & 1.01 \\
2 & Env. & 1 & 11 & 11 & 11 & 16.9 & 0.57 \\
3 & Env. & 3 & 11 & 33 & 33 & 12.4 & 1.25 \\
4 & Env. + Perf. & 3 & 10 & 30 & 30 & 12.6 & 1.20 \\
\hline
\end{tabular}

Table 9 - Capacity factors obtained for the optimum solution of each model. Note that Model 4 is the only model that has performance requirements.

\begin{tabular}{|c|c|c|c|c|c|c|c|c|c|c|c|c|c|c|}
\hline \multirow[b]{2}{*}{ Model } & \multicolumn{14}{|c|}{ Constraint } \\
\hline & $\begin{array}{c}\boldsymbol{C F}_{\text {Array }} \\
{[\%]}\end{array}$ & $\begin{array}{l}C F_{1} \\
{[\%]}\end{array}$ & $\begin{array}{l}\mathrm{CF}_{2} \\
{[\%]}\end{array}$ & $\begin{array}{l}\mathrm{CF}_{3} \\
{[\%]}\end{array}$ & $\begin{array}{l}\mathrm{CF}_{4} \\
{[\%]}\end{array}$ & $\begin{array}{l}\mathrm{CF}_{5} \\
{[\%]}\end{array}$ & $\begin{array}{l}\mathrm{CF}_{6} \\
{[\%]}\end{array}$ & $\begin{array}{l}\mathrm{CF}_{7} \\
{[\%]}\end{array}$ & $\begin{array}{l}\mathrm{CF}_{8} \\
{[\%]}\end{array}$ & $\begin{array}{l}\mathrm{CF}_{9} \\
{[\%]}\end{array}$ & $\begin{array}{l}F_{10} \\
{[\%]}\end{array}$ & $\begin{array}{l}C F_{11} \\
{[\%]}\end{array}$ & $\begin{array}{l}\mathrm{CF}_{12} \\
{[\%]}\end{array}$ & $\begin{array}{l}C_{13} \\
{[\%]}\end{array}$ \\
\hline 1 & 11.4 & 16.1 & 12.0 & 9.9 & 10.6 & 8.6 & --- & --- & --- & --- & --- & --- & --- & --- \\
\hline 2 & 16.9 & 16.9 & --- & --- & --- & --- & --- & --- & --- & --- & --- & --- & --- & --- \\
\hline 3 & 12.4 & 15.3 & 12.0 & 9.9 & --- & --- & --- & --- & --- & --- & --- & --- & --- & --- \\
\hline 4 & 12.6 & 15.3 & 12.2 & 10.1 & --- & --- & --- & --- & --- & --- & --- & --- & --- & --- \\
\hline
\end{tabular}


Table 10 - Discharge constraints values obtained with the optimum solution. $\Delta \Sigma Q$ represents the flood/ebb spring tide discharges for Faro-Olhão $\left(F o\right.$ ) and Armona ${ }_{A r}$ ) inlets, and $\Sigma Q_{A r} / \Sigma Q_{F O}$ their discharges ratio. Subscripts $f$ and $e$ depict for flood and ebb tides, respectively.

\begin{tabular}{|c|c|c|c|c|c|c|c|c|}
\hline \multirow[b]{2}{*}{ Model } & \multicolumn{8}{|c|}{ Constraint } \\
\hline & $\underset{[\%]}{\Delta \Sigma Q_{f, F O}}$ & $\underset{[\%]}{\Delta \Sigma Q_{f, A r}}$ & $\begin{array}{c}\Sigma Q_{f, A r} / \Sigma Q_{f, F O} \\
{[\%]}\end{array}$ & $\underset{[\%]}{\Delta \Sigma Q_{f, \text { all }}}$ & $\begin{array}{c}\Delta \Sigma Q_{e, F O} \\
{[\%]}\end{array}$ & $\begin{array}{c}\Delta \Sigma Q_{e, A r} \\
{[\%]}\end{array}$ & $\begin{array}{c}\Sigma Q_{e, A r} / \Sigma Q_{e, F O} \\
{[\%]}\end{array}$ & $\begin{array}{c}\Delta \Sigma Q_{e, \text { all }} \\
{[\%]}\end{array}$ \\
\hline 1 & -7.3 & 7.0 & 5.9 & -2.7 & -3.0 & 1.0 & 1.5 & -1.4 \\
\hline 3 & -8.7 & 7.5 & 6.8 & -3.4 & -4.1 & 1.2 & 2.0 & -1.9 \\
\hline 4 & -9.4 & 7.8 & 7.1 & -3.7 & -4.0 & 1.0 & 1.9 & -1.9 \\
\hline
\end{tabular}

Table 11 - Morphological constraints values obtained with the optimum solution. $\Delta V_{\text {net }}$ and $\Delta h_{\text {avg }}$ stand for the net sediment volume and average depth differences, respectively, for Faro-Olhão ( $F O)$ and Armona $\left({ }_{A r}\right)$ inlets.

\begin{tabular}{|c|c|c|c|c|}
\hline \multirow[b]{2}{*}{ Model } & \multicolumn{4}{|c|}{ Constraint } \\
\hline & $\Delta V_{n e t, F O}\left[\mathrm{~m}^{3} \cdot \mathrm{yr}^{-1}\right]$ & $\Delta V_{n e t, A r}\left[\mathrm{~m}^{3} \cdot \mathrm{yr}^{-1}\right]$ & $\Delta h_{\text {avg, }}$ FO $\left[\mathrm{cm} . \mathrm{yr}^{-1}\right]$ & $\Delta h_{a v g, ~} \operatorname{Ar}\left[\mathrm{cm} \mathrm{yr}^{-1}\right]$ \\
\hline 1 & -9475 & 33262 & -0.8 & 7.5 \\
\hline 2 & -5250 & 13390 & -0.6 & 3.2 \\
\hline 3 & -1232 & 35561 & 0.3 & 8.0 \\
\hline 4 & -3013 & 37019 & 0.1 & 8.4 \\
\hline
\end{tabular}

Under the constraints imposed, the results from the optimisation models reveal that 5 rows is the maximum allowable number of rows in a TEC array for the Faro-Olhão Inlet without adversely affecting the environment. For this particular case, each row contains 6 devices, resulting in a 30 turbine array. The associated power output of the array is of $1.01 \mathrm{GWh}_{\text {.year }}{ }^{-1}$ operating at a capacity factor of $11.4 \%$ (Table 8 ). The performance of three of the array rows is higher than $10 \%$ except for the third row, which is slightly lower $(9.9 \%)$ and for the fifth row drops to $8.6 \%$ (Table 9). On the other hand, the maximum capacity factor is obtained for the first row reaching $16.1 \%$. The lower capacity factor of row 5 is due to two main reasons: i) flow velocities are higher and stronger for most of the time at the throat of the inlet than in any other row of the potential array; and ii) due to depth constraints (TECs have to be positioned in regions with depths $\geq 10 \mathrm{~m}$ ), from the fifth row onwards, array rows have to be positioned aligned with the tidal channel causing the fastest flow on the ebb tide to miss these rows and to go straight to the fourth row. Then, row number 3, which is affected by the wakes of the second and fourth rows, sees its capacity factor $(9.9 \%)$ slightly reduced when compared to these two other rows. The most compromised discharge constraint (Table 10) is the Armona and Faro-Olhão flood discharge ratio attaining a $5.9 \%$ difference with a constraint value set to $7.5 \%$, while the less compromised is the Armona ebb discharge with a $1 \%$ difference with a constraint value set to $2.5 \%$. Concerning the morphological constraints (Table 11), the solution of Model 1 produces the largest impact in terms of deposition rates in the Faro-Olhão's flood delta, almost attaining the limit of 10,000 m.yr ${ }^{-1}$, while the effects on Armona's Inlet erosion rates are $17 \%$ less than the limit imposed (i.e. 40,000 $\mathrm{m}^{3}$ ). The optimum array solution of Model 1 does not jeopardise significantly the morphological constraints.

In Model 2, the maximum number of TECs per row in an array is 11, which is restricted to an array of just 1 row (Table 8). The capacity factor attained by this configuration is the highest of the four models reaching up to $16.9 \%$ (Table 9). Obviously, power outputs are the lowest $(0.57$ GWh.year $\left.{ }^{-1}\right)$, as a consequence of just operating 11 turbines. The impacts on discharges are the lowest of the four models with results comprising 4\% (i.e. Armona ebb discharge) to 33\% (i.e. Faro-Olhão flood discharge, and Armona and Faro-Olhão flood discharge ratio) of the constraints. 


\section{Pre-print}

In regard to morphological processes, in general, impacts are lower than for the rest of the optimisation models' solutions.

In Model 3, when optimising the maximum number of TECs in the array, results provide a solution with 3 rows and 11 TECs per row, which implies a total of 33 devices (Table 8). Array performance is $12.4 \%$, with capacity factors per row of $15.5 \% 15.3 \%, 12.0 \%$ and $9.9 \%$, for the first, second and third rows, respectively (Table 9). As expected, because it involves the largest number of turbines, this array configuration causes the larger impacts on tidal discharges, being the ratio between the Armona and Faro-Olhão inlets the most threatened constraint, with $6.8 \%$ almost attaining the limit value imposed of $7.5 \%$. The rest of the discharge constraints remain between $13 \%$ and $50 \%$ of the constraint limit. While erosion rates and average depth changes for Armona Inlet are the largest of the 4 models, sedimentation rates and average depth changes for the Faro-Olhão flood delta are the lowest. Moreover, for the Faro-Olhão flood delta average depth changes are not only the lowest of the four models but are also positive, which implies that within the flood delta there are regions of deposition and erosion when compared with the baseline case (i.e. without turbines).

Finally, results for Model 4, which considers both performance and environmental constraints, suggest an optimum array composed of 3 rows with 10 TECs per row (Table 8). The overall performance is $12.6 \%$ generating $1.2 \mathrm{GWh}_{\mathrm{yr}} \mathrm{y}^{-1}$ of power, $50 \mathrm{MW}$ less than the solution of Model 3 but with 3 less turbines. Capacity factors obtained represent no more than $5 \%$ of the minimum value imposed (Table 9). The slightly greater capacity factors of Model 4 respect to Model 3 are due to the fact that the drag produced by 10 TECs per row is lower than that caused by 11 TECs per row. In what respects to the environmental responses (Table 10 and Table 11), results align with the outputs from the previous models. Net volumes and average bottom depth changes for both inlets are also within the orders of magnitude expected if compared with results from models 1 and 2 .

\section{Discussion}

Results presented in Section 4, namely on the exploration of the TEC spatial disposition evidenced the positive/negative feedbacks between the two design variables when integrated in real cases with complex flow fields. The non-uniformity of tidal currents along the array region causes the variability of the resource in each row, as well as makes it difficult to predict the resultant array configuration interactions. Moreover, the inclusion of constraints into the array optimisation problem may lead to the conclusion that larger arrays, or the ones that generate more power, do not satisfy the conditions imposed, resulting in a solution economically and/or environmentally unfeasible. This evidence supports the work of du Feu et al. [59], where the optimum array layout that satisfies the environmental constraints has fewer turbines and a different turbine distribution than the solution without imposed restrictions.

Results from the optimisation models show that arrays larger than 3 rows see their efficiencies lessen, principally on the arrays rows positioned further inside the lagoon, where it is not possible to find a feasible solution for all rows with capacity factors greater than $10 \%$, as seen in models 1 and 3 solutions (Table 9). Therefore, for the Faro-Olhão Inlet, between the two design variables, the variable representing the number of rows in the array has a larger effect on the model solution than the number of TECs per row. In Table 8, the solutions for the 4 models provide optimum arrays containing the minimum and maximum number of TECs per row defined, i.e. $x_{2} \in[6,11]$, while for the variable defining the number of rows, the optimum solution of the largest array does not exceed 5 rows (Model 1). These results align with the findings of [16], [17], 


\section{Pre-print}

[60]. Vennel [16] concluded that the performance of TECs added to a row of a large array is a function of the characteristics of the deployment site, while in [17] the same author demonstrated that adding rows to an array may increase the overall total power output but at the cost of diminishing the individual output of each device within the array (refer to Fig. 10 to Fig. 12). Bucher and Couch [60] found a similar result in their study for the envisaged tidal array project Wando in Korea, where for all the array alternatives assessed they propose to use the ratio between installed capacity and capacity factor to define the optimum number of TECs and array characteristics.

Regarding the environmental requirements imposed, the most restrictive constraints are the flood tide discharge ratio between Armona and Faro-Olhão inlets, followed by the net volumes for Faro-Olhão flood delta and Armona inlets. This is a consequence of the strong relation between both inlets. Any change in one of them generates an immediate response on the other by adjustment to a new condition of equilibrium affecting both discharges and sediment dynamics [32], [33]. This effect is even more accentuated when the inlet where the arrays are placed has the largest discharges of the multi-inlet system, as is the case of the present case study.

In this particular application, the main disadvantage is that the size and configuration of the smallest and the largest array is predefined not allowing the number of turbines to be increased automatically and the individual devices to be positioned freely within the array deployment site, as in [20], [61]. When applying the SBO method, this limitation may be overcome during the problem formulation stage where the objective function and design variables are defined. In the TEC array layout problem, the objective function can represent several aspects involved in the design process like: array size, power output, capacity factor, etc. The design variables for defining an array layout are up to the choice of the designer and specific for each case. These can be, for example, the three-dimensional coordinates of each of the turbines that form the array but this choice brings the disadvantage that the position of each turbine will be a function of three design variables (i.e. corresponding to the Cartesian coordinate system for a three-dimensional space). It is important to notice that the number of numerical simulations needed to build the surrogates increases proportionally with the number of design variables defined, which makes unfeasible the 3D representation of each TEC in large arrays. For this reason, it is important to reduce, as much as possible, the number of design variables that define the array layout. Further research has to be conducted to formulate an SBO model for the TEC array problem allowing a free position of each device within the deployment region without compromising computational cost.

The placement of one or more TECs in a tidal stream alters the fluid velocity field in relation to that in the absence of turbines. As a result, the fluid velocity field has to be determined simultaneously with the placement of the TEC array rows [61], [62]. Thus, if analytical functions are used for mathematical optimisation it is necessary to ensure that these combined effects are well represented. It is for this reason that highly simplified formulations are not valid to assess array-flow interactions in real case scenarios involving unsteady and non-uniform flows, whereas SBO techniques can fill this gap.

\section{Conclusions}

This paper introduces a novel procedure to determine the maximum allowable capacity of a tidal inlet for tidal stream energy exploration using a surrogate-based optimisation, contemplating performance and environmental constraints of the whole system. A case study application for the Faro-Olhão Inlet in Ria Formosa, Portugal, has been presented. The procedure involves problem 


\section{Pre-print}

formulation, design variable selection, design of experiments, numerical simulations, surrogate model construction and validation, and constrained optimisation. The array size problem was formulated in terms of two design variables: number of array rows and number of tidal energy converters per row. Both design variables were related through the design of computer experiments considering a sample plan of 30 data points plus an additional 3 points for validation purposes. Computer experiments were executed using a 2D vertical averaged Delft3D hydromorphodynamic model for a time period of 1 year, where tidal energy converters where modelled using a porous plate approach. Each computational simulation provided a set of responses that included: array and rows capacity factors, cumulative instantaneous inlets discharges, net volumes of sedimentation and erosion, and changes in average depths. The sample plan data points were used to train linear radial basis functions surrogates of a total of 26 responses, then surrogates were validated against 3 data points. Finally, validated surrogates were employed to formulate multi-objective mathematical optimisation models considering environmental and performance constraints. Results suggest that: i) the maximum number of rows which do no cause detrimental environmental impacts is 5; ii) the array with the largest number of devices per row and the highest capacity factor that satisfies environmental constraints is made of 1 row with 11 turbines; iii) the maximum number of turbines that provides a feasible solution considering environmental constraints is 33 devices distributed in 3 rows with 11 tidal energy converter per row; and iv) the largest array that satisfies both sets of constraints, environmental and performance, is made of 3 rows with 10 devices per row.

The method reveals to be an interesting approach to optimise tidal energy converter arrays and to explore its effects on the environment, especially when placed in complex natural systems and the use of time-consuming numerical simulations is mandatory. For the study case presented in this paper, the optimisation method is based on finite difference 2D vertical averaged hydromorphodynamic computational simulations, which results in a limitation to capture accurately the lagoon hydro-morphodynamic responses and the complex flow-turbine interactions. However, this is a limitation restricted to this particular study as the surrogate-based optimisation methodology can be applied using high-definition 3D models and more sophisticated approaches to model tidal energy converters, which are important factors when optimising inter-device spacing within tidal arrays.

The main advantages of using the surrogate-based approach for optimising tidal energy arrays are summarised as follows:

- It is a very advantageous approach to be used in problems that comprise time-consuming numerical simulations;

- Surrogates can approximate responses, computed using high-definition numerical simulations, as a function of several design parameters that otherwise will be difficult to represent with simple analytical functions (e.g. wake deficit models);

- Surrogates can represent the objective function, the constraints or both;

- There are several mathematical functions available to be employed as surrogates, e.g. polynomials, radial basis functions, kriging models;

- Allows to determine an optimal solution under a series of constraints:

- The optimisation model can be formulated incorporating complex constraints such as hydro-morphological processes and turbine performance (e.g. capacity factor, rotor load forces, diameter size); and

- In cases with multiple design variables, when modifying constraints limits, the surrogatebased approach method becomes very convenient to search all the variable domain space for feasible solutions at an affordable computational time. 


\section{Pre-print}

It is important to mention that the main aims of the problem formulation and constraints presented in this paper are to illustrate the capabilities of the methodology and to provide some examples on how to optimise the size of a tidal energy converter array in a tidal inlet, which can then be applied worldwide to similar environmental conditions (e.g. lagoons, estuaries, inlets). There is more than one manner to formulate the aforementioned optimisation problem. Therefore, in a real case scenario, the objective function, the constraints and their limits should be set considering the opinion of the stakeholders involved in the project domain (i.e. project developer, port authorities, fishermen communities, aquaculture farmers, etc) and if possible by a consensus [63]. This way, the capabilities and applications of the surrogate-based approach for optimising tidal arrays are wide and promising. Moreover, while here it is presented an application for the tidal energy sector, the surrogate-based approach is not restricted to this area and it can be further applied to optimise, for example, wave energy farms as well as onshore and offshore wind energy farms. However, each real application will need a specific definition of design variables, objective functions and constraints.

Future work is directed towards sophisticating the optimisation model by: 1) including an economic model allowing to optimise the problem in terms of minimising the levelised cost of energy; 2) considering new design variables to allow the siting of different turbine sizes and the positioning of individual array rows independently from the others; and 3) incorporating other environmental factors (e.g. water quality) in the numeric simulations to account for additional constraints.

\section{Acknowledgment}

Eduardo González-Gorbeña has received funding for the OpTiCA project from the Marie Skłodowska-Curie Actions of the European Union's H2020-MSCA-IF-EF-RI-2016 / under REA grant agreement $\mathrm{n}^{\circ}$ [748747]. The paper is a contribution to the SCORE project, funded by the Portuguese Foundation for Science and Technology (FCT - PTDC/AAG-TEC/1710/2014). André Pacheco was supported by the Portuguese Foundation for Science and Technology under the Portuguese Researchers' Programme 2014 entitled "Exploring new concepts for extracting energy from tides" (IF/00286/2014/CP1234).

\section{References}

[1] K. Johnson, G. Dalton, and I. Masters, (Eds.), "Chapter 4: Ocean Energy - Wave and Tide," In Building Industries at Sea: Blue Growth and the New Maritime Economy, River Publishers, pp. 137-184, 2018. Doi: $10.13052 / \mathrm{rp}-9788793609259$

[2] J. Xia, R. A. Falconer, and B. Lin, "Numerical model assessment of tidal stream energy resources in the Severn Estuary, UK," Proc. IMechE Part A: J. Power and Energy, vol. 224, pp. 969-983, 2010. Doi: 10.1243/09576509JPE938

[3] F. O'Rourke, F. Boyle, and A. Reynolds, "Ireland's tidal energy resource; An assessment of a site in the Bulls Mouth and the Shannon Estuary using measured data," Energy Conversion and Management, vol. 87, pp. 726-734, 2014. Doi: 10.1016/j.enconman.2014.06.089

[4] R. Carballo, G. Iglesias, A. Castro, "Numerical model evaluation of tidal stream energy resources in the Ría de Muros (NW Spain)," Renewable Energy, vol. 34, pp. 1517-1524, 2009. Doi: $10.1016 /$ j.renene.2008.10.028 


\section{Pre-print}

[5] A. Pacheco and O. Ferreira, R. Carballo, and G. Iglesias, "Evaluation of the tidal stream energy production at an inlet channel coupling field data and modelling," Energy, vol. 71, pp. 104-117, 2014. Doi: 10.1016/j.energy.2014.04.075

[6] M. Willis, I. Masters, S. Thomas, R. Gallie, J. Loman, A. Cook, and M. Cross, "Tidal turbine deployment in the Bristol Channel: a case study," Proceedings of the Institution of Civil Engineers-Energy, vol. 163, np. 3, pp. 93-105, 2010. Doi: 10.1680/ener.2010.163.3.93

[7] M. Shields, M. Woolf, E. Grist, S. Kerr, A. Jackson, R. Harris, M. Bell, R. Beharie, A. Want, E. Osalusi, S. Gibb, and J. Side, "Marine Renewable Energy: the ecological implications of altering the hydrodynamics on the marine environment," Ocean Coastal Management, vol. 54, pp. 2-9, 2011. Doi: 10.1016/j.ocecoaman.2010.10.036

[8] M. Kadiri, R. Ahmadian, B. Bockelmann-Evans, W. Rauen, and R. Falconer, "A review of the potential water quality impacts of tidal renewable energy systems," Renewable and Sustainable Energy Review, vol. 16, no. 1, pp. 329-341, 2012. Doi: 10.1016/j.rser.2011.07.160

[9] A. Copping, "Environmental effects of marine energy development around the world: Annex IV, Final Report," Pacific Northwest National Laboratory, 2013.

[10] C. Frid, E. Andonegi, J. Depestele, A. Judd, D. Rihan, S.I. Rogers, and E. Kenchington, "The environmental interactions of tidal and wave energy generation devices," Environmental Impact Assessment Review, vol. 32, no. 1, pp. 133-139, 2012. Doi: 10.1016/j.eiar.2011.06.002

[11] E. González-Gorbeña, G. Jr. Geraldo, R. Y. Qassim, and P. C. Rosman, "Influence in sediment dynamics due to tidal energy farms at São Marcos Bay, Ma," Revista Brasileira de Recursos Hídricos, vol. 20, no. 2, pp. 379-393, 2015 (In Portuguese). Doi: $\underline{10.21168 / \text { rbrh.v20n2.p379-393 }}$

[12] P. E. Robins, S. P. Neill, M. J. Lewis, "Impact of tidal-stream arrays in relation to the natural variability of sedimentary processes," Renewable Energy, vol. 72, pp. 311-321, 2014. Doi: 10.1016/j.renene.2014.07.037

[13] I. Fairley, H. Karunarathna, I. Masters, " The influence of waves on morphodynamic impacts of energy extraction at a tidal stream turbine site in the Pentland Firth," Renewable Energy, vol. 125, pp. 630-647, 2018. Doi: 10.1016/j.renene.2018.02.035

[14] J. Thiébot, P. B. du Bois, S. Guillou, "Numerical modeling of the effect of tidal stream turbines on the hydrodynamics and the sediment transport-Application to the Alderney Race (Raz Blanchard), France," Renewable Energy, vol. 75, pp. 356-365, 2015. Doi: 10.1016/j.renene.2014.10.021

[15] C. Garrett and P. Cummins, "The efficiency of a turbine in a tidal channel," Journal of Fluid Mechanics, vol. 588, pp. 243-251, 2007. Doi: 10.1017/S0022112007007781

[16] R. Vennell, "Tuning turbines in a tidal channel," Journal of Fluid Mechanics, vol. 663, pp 253-267, 2010. Doi: 10.1017/S0022112010003502

[17] R. Vennell, "The energetics of large tidal turbine arrays," Renewable Energy, vol. 48, pp. 210-219, 2012. Doi: 10.1016/j.renene.2012.04.018 


\section{Pre-print}

[18] T. Nishino, and R. H. Willden, "The efficiency of an array of tidal turbines partially blocking a wide channel," Journal of Fluid Mechanics, vol. 708, pp. 596-606, 2012. Doi: 10.1017/jfm.2012.349

[19] G. T. Houlsby, S, Draper, and M. L. G, Oldfield, "Application of linear momentum actuator disc theory to open channel flow," Report no. OUEL, 2296(08), 2008.

[20] O. A. L. Brutto, J. Thiébot, S. S. Guillou, H. Gualous, "A semi-analytic method to optimize tidal farm layouts-Application to the Alderney Race (Raz Blanchard) Fr," Applied Energy, vol. 183, pp. 1168-1180, 2016. Doi: 10.1016/j.apenergy.2016.09.059

[21] M. Sánchez, R. Carballo, V. Ramos, G. Iglesias, "Tidal stream energy impact on the transient and residual flow in an estuary: a 3D analysis," Applied Energy, vol. 116, pp. 167-177, 2014. Doi: $\underline{10.1016 / \mathrm{j} . \text { apenergy.2013.11.052 }}$

[22] N. Guillou, G. Chapalain, "Assessing the impact of tidal stream energy extraction on the Lagrangian circulation,” Applied Energy, vol. 203, pp. 321-332, 2017. Doi: $\underline{10.1016 / j . a p e n e r g y .2017 .06 .022}$

[23] S. Koziel, and L. Leifsson, Surrogate-based modeling and optimization: Applications in Engineering. Springer-Verlag, NY, 2013. Doi: 10.1007/978-1-4614-7551-4

[24] E. González-Gorbeña, R. Y. Qassim, and P. C. Rosman, "Optimisation of hydrokinetic turbine array layouts via surrogate modelling," Renewable Energy, vol. 93, pp. 45-57, 2016. Doi: $\underline{10.1016 / j . r e n e n e .2016 .02 .045}$

[25] E. González-Gorbeña, R. Y. Qassim, and P. C Rosman, "Multi-dimensional Optimisation of Tidal Energy Converters Array Layouts Considering Geometric, Economic and Environmental Constraints." Renewable Energy, vol. 116 (A), pp. 647-658, 2018. Doi: 10.1016/j.renene.2017.10.009

[26] A. Forrester, A. Sobester, and A. Keane, Engineering design via surrogate modelling: a practical guide, John Wiley \& Sons, 2008.

[27] L. P. Almeida, M. V. Vousdoukas, O. Ferreira, B.A. Rodrigues, A. Matias, "Thresholds for storm impacts on an exposed sandy coastal area in southern Portugal," Geomorphology, vol. 143-144, no. 0, pp. 3-12, 2012. Doi: 10.1016/j.geomorph.2011.04.047

[28] T. A. Plomaritis, J. Benavente, I. Laiz, L. Del Rio, "Variability in storm climate along the Gulf of Cadiz: the role of large scale atmospheric forcing and implications to coastal hazards," Climate Dynamics, vol. 45, no. 9-10, pp. 2499-2514, 2015. Doi: 10.1007/s00382-015-2486-4

[29] M. Costa, R, Silva, and J, Vitorino, "Contribuição para o estudo do clima de agitação marítima na costa Portuguesa," in Proc. 2as Jornadas Portuguesas de Engenharia Costeira e Portuária, 2001 (in Portuguese).

[30] A. Newton, and S. M. Mudge "Temperature and salinity regimes in a shallow, mesotidal lagoon, the Ria Formosa, Portugal," Estuarine, Coastal and Shelf Science, vol. 57, pp. 73-85, 2003. Doi: $\underline{10.1016 / \mathrm{S} 0272-7714(02) 00332-3}$ 


\section{Pre-print}

[31] A. Picado, C. L. Lopes, R. Mendes, N. Vaz, and J. M. Dias, "Storm surge impact in the hydrodynamics of a tidal lagoon: the case of Ria de Aveiro," Journal of Coastal Research Special Issue No. 65, International Coastal Symposium Vol. 1, pp. 796-801, 2013. Doi: $\underline{10.2112 / \text { SI } 65-135.1}$

[32] J. P. F. Fabião, M. F. G. Rodrigues, A. B. Fortunato, J. M. Q. de Brito Jacob, and A. M. F.Cravo, "Water exchanges between a multi-inlet lagoon and the ocean: the role of forcing mechanisms," Ocean Dynamics, vol. 66, no. 2, pp. 173-194, 2016. Doi: 10.1007/s10236-015$\underline{0918-7}$

[33] A. Pacheco, A. Vila-Concejo, Ó. Ferreira, and J.A. Dias, “Assessment of Tidal Inlet Evolution and Stability Using Sediment Budget Computations and Hydraulic Parameter Analysis,” Marine Geology, vol. 247, pp. 104-127, 2008. Doi: 10.1016/j.margeo.2007.07.003

[34] E. González-Gorbeña, A. Pacheco, T. A. Plomaritis, and C. Sequeira, “Assessing the Effects of Tidal Energy Converter Array Size on Hydrodynamics of Ria Formosa (Portugal)," Proceedings of the $12^{\text {th }}$ European Wave and Tidal Energy Conference, Cork, Ireland, 2018.

[35] G. Lesser, J.A. Roelvink, J.A.T.M. Van Kester, G.S. Stelling, "Development and validation of a three-dimensional morphological model," Coastal Engineering vol. 51, pp. 883-915, 2004. Doi: 10.1016/j.coastaleng.2004.07.014

[36] L. Boudet, F. Sabatier, and O. Radakovitch, "Modelling of sediment transport pattern in the mouth of the Rhone delta: Role of storm and flood events," Estuarine, Coastal and Shelf Science, vol. 198, pp. 568-582, 2017. Doi: 10.1016/j.ecss.2016.10.004

[37] A. P. Luijendijk, R. Ranasinghe, M.A. de Schipper, B.A. Huisman, C. M. Swinkels, D. J. Walstra, and M.J. Stive, "The initial morphological response of the Sand Engine: A processbased modelling study," Coastal engineering, vol. 119, pp. 1-14, 2017. Doi:

10.1016/j.coastaleng.2016.09.005

[38] SCORE - Sustainability of using Ria Formosa Currents On Renewable Energy production. Funded by the Portuguese Foundation for Science and Technology (FCT - PTDC/AAGTEC/1710/2014). Last accessed on: 31/05/2018. Link: http://w3.ualg.pt/ ampacheco/Score/index.html

[39] SCORE project database. Last accessed on: 03/09/2018. Link: http://w3.ualg.pt/ ampacheco/Score/database.html

[40] C. F. Colebrook, "Correspondence. turbulent flow in pipes, with particular reference to the transition region between the smooth and rough pipe laws.(includes plates)," Journal of the Institution of Civil Engineers, vol. 11, no. 4, pp. 133-156, 1939. Doi: 10.1680/ijoti.1939.13150

[41] R. Courant, K. Friedrichs, and H. Lewy, "Über die partiellen Differenzengleichungen der mathematischen Physik," Mathematische annalen, vol. 100, no. 1, pp. 32-74, 1928.

[42] R. Rana-singhe, C. Swinkels, A. Luijendijk, D. Roelvink, J., Bosboom, M. Stive, D. Walstra, "Morphodynamic upscaling with the MORFAC approach: Dependencies and sensitivities," Coastal Engineering, vol. 58, no. 8, pp. 806-811, 2011. Doi:

10.1016/j.coastaleng.2011.03.010 


\section{Pre-print}

[43] G. R. Lesser, “An Approach to Medium-term Coastal Morphological Modelling,” $\mathrm{PhD}$ Thesis: UNESCO-IHE \& Delft Technical University, 2009.

[44] J. D. Rosati, "Concepts in sediment budgets," Journal of Coastal Research, vol. 21, no. 2, pp. 307-322, 2005. Doi: 10.2112/02-475A.1

[45] D. Roelvink and A. Reniers. A guide to modeling coastal morphology (Vol. 12). World Scientific, 2011.

[46] A. Pacheco, J.J. Williams, Ó. Ferreira, E. Garel, and S. Reynolds, “Application of sediment transport models to a multiple-inlet system. estuarine," Coastal and Shelf Science, vol. 95, pp. 119-134, 2011. Doi: 10.1016/j.ecss.2011.08.027

[47] A. Pacheco and O. Ferreira, "Hydrodynamic changes imposed by tidal energy converters on extracting energy on a real case scenario," Applied Energy, vol. 180, pp. 369-385, 2016. Doi: $\underline{10.1016 / j . a p e n e r g y .2016 .07 .132}$

[48] S. C. James, E. L. Johnson, J. Barco, J. D. Roberts. Simulating current-energy converters: SNL-EFDC model development, verification, and parameter estimation. Renewable Energy, 2017 (In Press). Doi: 10.1016/j.renene.2017.07.020

[49] P. A. Work, K. A. Haas, Z. Defne, Z., T. Gay, "Tidal stream energy site assessment via three-dimensional model and measurements," Applied energy, vol. 102, pp. 510-519, 2013. Doi: $\underline{10.1016 / j . a p e n e r g y .2012 .08 .040}$

[50] E. González-Gorbeña, P. C. C. Rosman, R. Y. Qassim, “Assessment of the Tidal Current Energy Resource in São Marcos Bay, Brazil," Journal of Ocean Engineering and Marine Energy, vol. 1, no. 4, pp. 421-433, 2015. Doi: 10.1007/s40722-015-0031-5

[51] C. S. Jonathan (Ed.), "Terawatt Position Papers: A Toolbox of Methods to Better Understand and Assess the Effects of Tidal and Wave Energy Arrays on the Marine Environment," Marine Alliance for Science and Technology for Scotland, p. 166, 2015.

[52] A. Pacheco, E. Gorbeña, T. A. Plomaritis, E. Garel, J. M. S. Gonçalves, L. Bentes, Monteiro, C. M. L Afonso, F. Oliveira, C. Soares, F. Zabel, C. Sequeira, "Deployment characterization of a floatable tidal energy converter on a tidal channel, Ria Formosa, Portugal," Energy, vol. 158, pp. 89-104, 2018. Doi: 10.1016/j.energy.2018.06.034

[53] T. Stallard, R. Collings, T. Feng, and J. Whelan, "Interactions between tidal turbine wakes: experimental study of a group of three-bladed rotors," Phil. Trans. R. Soc. A, vol. 371, no. 1985, 20120159, 2013. Doi: 10.1098/rsta.2012.0159

[54] J. L. Loeppky, J. Sacks, and W.J. Welch, "Choosing the sample size of a computer experiment: A practical guide.” Technometrics, vol. 51, pp. 366-376, 2009. Doi: $\underline{10.1198 / \text { TECH.2009.08040 }}$

[55] M. I. Santos. Construção de metamodelos de regressão não linear para simulação de acontecimentos discretos. PhD Thesis, Universidade Técnica de Lisboa; 2002 (In-Portuguese). 


\section{Pre-print}

[56] Z. Nedělkova, P. Lindroth, A.-B. Ströberg, and M. Patriksson, "Integration of expert knowledge into radial basis function surrogate models," Optimization and Engineering, vol. 17, no. 3, pp. 1-27, 2015. Doi: 10.1007/s11081-015-9297-7

[57] A. Pacheco, Ó. Ferreira, J. J. Williams, "Long-term Morphological Impacts of the Opening of a New Inlet on a Multiple Inlet System," Earth Surface Processes and Landforms, vol. 36, pp. 1726-1735. Doi: $\underline{10.1002 / e s p .2193}$

[58] P. Venkataraman, Applied Optimization with Matlab Programming, John Wiley \& Sons, 2001.

[59] R. J. du Feu, S. W. Funke, S. C. Kramer, D. M. Culley, J. Hill, B. S. Halpern, M. D. Piggott, "The trade-off between tidal-turbine array yield and impact on flow: A multi-objective optimisation problem," Renewable Energy, vol. 114, pp. 1247-1257, 2017. Doi: $\underline{10.1016 / j . r e n e n e .2017 .07 .081}$

[60] R. Bucher, and S.J. Couch, "Adjusting the financial risk of tidal current projects by optimising the 'installed capacity/capacity factor'-ratio already during the feasibility stage," International Journal of Marine Energy vol. 2, pp. 28-42, 2012. Doi: $\underline{10.1016 / j . i j o m e .2013 .05 .008}$

[61] S.W. Funke, S. C. Kramer, and M. D. Piggott, (2016). Design optimisation and resource assessment for tidal-stream renewable energy farms using a new continuous turbine approach. Renewable Energy, vol. 99, pp. 1046-1061, 2016. Doi: 10.1016/j.renene.2016.07.039

[62] R. Vennell, S.W. Funke, S. Draper, C. Stevens, T. Divett "Designing large arrays of tidal turbines: A synthesis and review," Renewable and Sustainable Energy Reviews, vol. 41, pp. 454-472, 2015. Doi: 10.1016/j.rser.2014.08.022

[63] K. Barquet, L. Cumiskey, "Using participatory Multi-Criteria Assessments for assessing disaster risk reduction measures," Coastal Engineering, vol. 134, pp. 93-102, 2018. Doi:

10.1016/j.coastaleng.2017.08.006

[64] G. D. Egbert, and S. Y. Erofeeva, "Efficient Inverse Modeling of Barotropic Ocean Tides," Journal of Atmospheric and Oceanic Technology, vol. 19, pp. 183-204, 2002. Doi: 10.1175/1520-0426(2002)019<0183:EIMOBO>2.0.CO;2 


\section{APPENDIX}

\section{Appendix A: Results from the computational experiments}

Table A.1 - Capacity factors, $C F$, as a function of the two design variables (i.e. $x_{1}$ and $x_{2}$ ), obtained for each computational experiment defined in Fig. 8. Capacity factors are for the whole array and for each rows that form the array. An array with just 1 row (e.g. cases 1, 4 and 18), the capacity factor for rows 2 to 13 will be 0 .

\begin{tabular}{|c|c|c|c|c|c|c|c|c|c|c|c|c|c|c|c|c|}
\hline Case & $\begin{array}{c}x_{1} \\
\text { [rows] }\end{array}$ & $\begin{array}{c}x_{2} \\
{[\text { TECs/row] }}\end{array}$ & $\begin{array}{c}\boldsymbol{C F}_{\text {Array }} \\
{[\%]}\end{array}$ & $\begin{array}{l}\mathrm{CF}_{1} \\
{[\%]}\end{array}$ & $\begin{array}{l}\mathrm{CF}_{2} \\
{[\%]}\end{array}$ & $\begin{array}{l}\mathrm{CF}_{3} \\
{[\%]}\end{array}$ & $\begin{array}{l}\mathrm{CF}_{4} \\
{[\%]}\end{array}$ & $\begin{array}{l}\mathrm{CF}_{5} \\
{[\%]}\end{array}$ & $\begin{array}{l}\mathrm{CF}_{6} \\
{[\%]}\end{array}$ & $\begin{array}{l}\mathrm{CF}_{7} \\
{[\%]}\end{array}$ & $\begin{array}{l}\mathrm{CF}_{8} \\
{[\%]}\end{array}$ & $\begin{array}{l}\mathrm{CF}_{9} \\
{[\%]}\end{array}$ & $\begin{array}{l}\mathrm{CF}_{10} \\
{[\%]}\end{array}$ & $\begin{array}{l}C F_{11} \\
{[\%]}\end{array}$ & $\begin{array}{l}\mathrm{CF}_{12} \\
{[\%]}\end{array}$ & $\begin{array}{l}\mathrm{CF}_{13} \\
{[\%]}\end{array}$ \\
\hline 1 & 1 & 11 & 16.9 & 16.9 & 0.0 & 0.0 & 0.0 & 0.0 & 0.0 & 0.0 & 0.0 & 0.0 & 0.0 & 0.0 & 0.0 & 0.0 \\
\hline 2 & 13 & 11 & 5.2 & 13.4 & 11.2 & 8.3 & 7.8 & 5.5 & 3.9 & 2.8 & 2.8 & 3.1 & 3.2 & 2.1 & 1.8 & 1.2 \\
\hline 3 & 13 & 6 & 6.2 & 14.9 & 12.0 & 9.8 & 9.9 & 6.9 & 5.4 & 3.8 & 3.2 & 3.2 & 3.7 & 3.0 & 2.7 & 1.6 \\
\hline 4 & 1 & 6 & 18.0 & 18.0 & 0.0 & 0.0 & 0.0 & 0.0 & 0.0 & 0.0 & 0.0 & 0.0 & 0.0 & 0.0 & 0.0 & 0.0 \\
\hline 5 & 4 & 11 & 11.5 & 14.9 & 11.7 & 9.5 & 9.9 & 0.0 & 0.0 & 0.0 & 0.0 & 0.0 & 0.0 & 0.0 & 0.0 & 0.0 \\
\hline 6 & 7 & 11 & 8.0 & 13.7 & 10.8 & 7.9 & 7.3 & 6.5 & 4.9 & 4.6 & 0.0 & 0.0 & 0.0 & 0.0 & 0.0 & 0.0 \\
\hline 7 & 10 & 11 & 6.2 & 13.6 & 11.2 & 8.3 & 7.8 & 5.7 & 4.2 & 3.0 & 2.8 & 2.8 & 3.1 & 0.0 & 0.0 & 0.0 \\
\hline 8 & 2 & 10 & 13.9 & 15.5 & 12.3 & 0.0 & 0.0 & 0.0 & 0.0 & 0.0 & 0.0 & 0.0 & 0.0 & 0.0 & 0.0 & 0.0 \\
\hline 9 & 6 & 10 & 9.2 & 14.1 & 10.9 & 8.2 & 7.9 & 7.7 & 6.3 & 0.0 & 0.0 & 0.0 & 0.0 & 0.0 & 0.0 & 0.0 \\
\hline 10 & 8 & 10 & 7.5 & 13.9 & 11.2 & 8.3 & 7.9 & 6.3 & 4.6 & 3.8 & 4.1 & 0.0 & 0.0 & 0.0 & 0.0 & 0.0 \\
\hline 11 & 12 & 10 & 5.7 & 13.7 & 11.4 & 8.6 & 8.1 & 5.7 & 4.1 & 3.0 & 2.8 & 3.1 & 3.2 & 2.4 & 2.3 & 0.0 \\
\hline 12 & 3 & 9 & 12.8 & 15.8 & 12.4 & 10.3 & 0.0 & 0.0 & 0.0 & 0.0 & 0.0 & 0.0 & 0.0 & 0.0 & 0.0 & 0.0 \\
\hline 13 & 5 & 9 & 10.7 & 14.8 & 11.3 & 9.0 & 9.3 & 9.0 & 0.0 & 0.0 & 0.0 & 0.0 & 0.0 & 0.0 & 0.0 & 0.0 \\
\hline 14 & 7 & 9 & 8.5 & 14.3 & 11.2 & 8.5 & 8.1 & 7.0 & 5.4 & 4.9 & 0.0 & 0.0 & 0.0 & 0.0 & 0.0 & 0.0 \\
\hline 15 & 9 & 9 & 7.1 & 14.1 & 11.5 & 8.8 & 8.4 & 6.4 & 4.8 & 3.6 & 3.4 & 3.3 & 0.0 & 0.0 & 0.0 & 0.0 \\
\hline 16 & 11 & 9 & 6.2 & 14.0 & 11.7 & 8.9 & 8.6 & 6.1 & 4.5 & 3.2 & 2.9 & 3.0 & 3.2 & 2.6 & 0.0 & 0.0 \\
\hline 17 & 13 & 9 & 5.5 & 13.9 & 11.6 & 8.9 & 8.5 & 6.0 & 4.3 & 3.1 & 2.9 & 3.2 & 3.4 & 2.4 & 2.1 & 1.3 \\
\hline 18 & 1 & 8 & 17.5 & 17.5 & 0.0 & 0.0 & 0.0 & 0.0 & 0.0 & 0.0 & 0.0 & 0.0 & 0.0 & 0.0 & 0.0 & 0.0 \\
\hline 19 & 3 & 8 & 13.0 & 16.1 & 12.4 & 10.4 & 0.0 & 0.0 & 0.0 & 0.0 & 0.0 & 0.0 & 0.0 & 0.0 & 0.0 & 0.0 \\
\hline 20 & 5 & 8 & 11.0 & 15.2 & 11.5 & 9.3 & 9.7 & 9.2 & 0.0 & 0.0 & 0.0 & 0.0 & 0.0 & 0.0 & 0.0 & 0.0 \\
\hline 21 & 7 & 8 & 9.9 & 15.2 & 11.5 & 9.3 & 9.7 & 9.2 & 7.8 & 6.4 & 0.0 & 0.0 & 0.0 & 0.0 & 0.0 & 0.0 \\
\hline 22 & 9 & 8 & 7.4 & 14.4 & 11.7 & 9.1 & 8.9 & 6.7 & 5.1 & 3.8 & 3.5 & 3.3 & 0.0 & 0.0 & 0.0 & 0.0 \\
\hline 23 & 11 & 8 & 6.5 & 14.3 & 11.9 & 9.3 & 9.1 & 6.4 & 4.8 & 3.3 & 2.9 & 3.0 & 3.3 & 2.8 & 0.0 & 0.0 \\
\hline 24 & 2 & 7 & 14.5 & 16.5 & 12.5 & 0.0 & 0.0 & 0.0 & 0.0 & 0.0 & 0.0 & 0.0 & 0.0 & 0.0 & 0.0 & 0.0 \\
\hline 25 & 6 & 7 & 10.1 & 15.3 & 11.4 & 9.1 & 9.3 & 8.5 & 7.1 & 0.0 & 0.0 & 0.0 & 0.0 & 0.0 & 0.0 & 0.0 \\
\hline 26 & 8 & 7 & 8.3 & 14.9 & 11.6 & 9.2 & 9.2 & 7.1 & 5.6 & 4.4 & 4.2 & 0.0 & 0.0 & 0.0 & 0.0 & 0.0 \\
\hline 27 & 12 & 7 & 6.3 & 14.6 & 11.9 & 9.5 & 9.4 & 6.6 & 5.0 & 3.5 & 3.1 & 3.2 & 3.6 & 2.9 & 2.7 & 0.0 \\
\hline 28 & 4 & 6 & 12.8 & 16.6 & 12.4 & 10.4 & 11.6 & 0.0 & 0.0 & 0.0 & 0.0 & 0.0 & 0.0 & 0.0 & 0.0 & 0.0 \\
\hline 29 & 7 & 6 & 9.4 & 15.5 & 11.6 & 9.4 & 9.6 & 7.9 & 6.5 & 5.4 & 0.0 & 0.0 & 0.0 & 0.0 & 0.0 & 0.0 \\
\hline 30 & 10 & 6 & 7.4 & 15.1 & 12.0 & 9.8 & 10.1 & 7.2 & 5.7 & 4.0 & 3.2 & 3.0 & 3.7 & 0.0 & 0.0 & 0.0 \\
\hline 31 & 3 & 7 & 13.2 & 16.5 & 12.5 & 10.5 & 0.0 & 0.0 & 0.0 & 0.0 & 0.0 & 0.0 & 0.0 & 0.0 & 0.0 & 0.0 \\
\hline 32 & 4 & 10 & 11.8 & 15.2 & 11.9 & 9.7 & 10.3 & 0.0 & 0.0 & 0.0 & 0.0 & 0.0 & 0.0 & 0.0 & 0.0 & 0.0 \\
\hline 33 & 13 & 8 & 5.7 & 14.2 & 11.8 & 9.2 & 8.9 & 6.3 & 4.6 & 3.3 & 3.0 & 3.2 & 3.5 & 2.6 & 2.3 & 1.4 \\
\hline
\end{tabular}

Table A.2 - Percent differences respect to the baseline case of cumulative flood discharges for a spring tide as a function of the two design variables (i.e. $x_{1}$ and $x_{2}$ ), obtained for each computational experiment defined in Fig. 8. The baseline flood-discharge ratio between Armona and Faro-Olhão inlets is $37.8 \%$.

Differences in instantaneous cumulative flood discharges, [\%]

\begin{tabular}{|c|c|c|c|c|c|c|c|c|c|}
\hline Case & $\begin{array}{c}x_{1} \\
{[\text { rows] }}\end{array}$ & $\begin{array}{c}x_{2} \\
{[\text { TECs/row] }}\end{array}$ & Ancão & $\begin{array}{l}\text { Faro- } \\
\text { Olhão }\end{array}$ & Armona & Fuseta & Tavira & All inlets & $\begin{array}{r}\text { Ratio } \\
\text { Ar/FO }\end{array}$ \\
\hline 1 & 1 & 11 & 1.6 & -3.1 & 3.3 & 0.4 & -0.1 & -1.0 & 2.5 \\
\hline 2 & 13 & 11 & 9.6 & -18.5 & 19.1 & 2.7 & -0.1 & -6.4 & 17.5 \\
\hline 3 & 13 & 6 & 5.7 & -11.5 & 13.0 & 1.9 & 0.0 & -3.7 & 10.4 \\
\hline 4 & 1 & 6 & 0.8 & -1.5 & 1.8 & 0.2 & 0.0 & -0.4 & 1.2 \\
\hline 5 & 4 & 11 & 4.8 & -11.2 & 9.3 & 1.3 & -0.1 & -4.4 & 8.7 \\
\hline 6 & 7 & 11 & 7.3 & -16.0 & 14.1 & 1.9 & 0.0 & -6.1 & 13.5 \\
\hline 7 & 10 & 11 & 8.6 & -17.9 & 17.7 & 2.5 & 0.0 & -6.4 & 16.4 \\
\hline 8 & 2 & 10 & 3.8 & -8.8 & 7.2 & 0.9 & 0.0 & -3.5 & 6.7 \\
\hline 9 & 6 & 10 & 6.1 & -14.0 & 12.3 & 1.7 & 0.0 & -5.4 & 11.6 \\
\hline 10 & 8 & 10 & 7.1 & -15.5 & 14.4 & 2.1 & 0.0 & -5.7 & 13.4 \\
\hline 11 & 12 & 10 & 8.9 & -17.3 & 17.9 & 2.6 & 0.0 & -6.0 & 16.1 \\
\hline 12 & 3 & 9 & 2.8 & -7.9 & 6.5 & 0.8 & -0.1 & -3.1 & 5.9 \\
\hline 13 & 5 & 9 & 4.8 & -11.5 & 10.2 & 1.4 & -0.1 & -4.4 & 9.3 \\
\hline
\end{tabular}


Pre-print

\begin{tabular}{cccccccccc}
\hline 14 & 7 & 9 & 6.3 & -13.6 & 12.5 & 1.7 & 0.0 & -5.0 & 11.4 \\
15 & 9 & 9 & 7.0 & -15.0 & 14.7 & 2.1 & -0.1 & -5.3 & 13.2 \\
16 & 11 & 9 & 8.4 & -15.8 & 16.4 & 2.4 & 0.0 & -5.5 & 14.5 \\
17 & 13 & 9 & 7.5 & -16.2 & 17.0 & 2.5 & 0.0 & -5.5 & 15.0 \\
18 & 1 & 8 & 1.1 & -2.2 & 2.4 & 0.2 & 0.0 & -0.7 & 1.8 \\
19 & 3 & 8 & 2.7 & -7.0 & 5.9 & 0.7 & -0.1 & -2.7 & 5.2 \\
20 & 5 & 8 & 4.0 & -10.2 & 9.2 & 1.2 & 0.0 & -3.8 & 8.2 \\
21 & 7 & 8 & 4.0 & -10.2 & 9.2 & 1.2 & 0.0 & -3.8 & 8.2 \\
22 & 9 & 8 & 6.5 & -13.7 & 13.6 & 1.9 & 0.0 & -4.8 & 12.0 \\
23 & 11 & 8 & 7.6 & -14.5 & 15.2 & 2.2 & 0.0 & -5.0 & 13.2 \\
24 & 2 & 7 & 2.5 & -6.1 & 5.2 & 0.7 & 0.0 & -2.4 & 4.5 \\
25 & 6 & 7 & 4.8 & -9.8 & 9.4 & 1.3 & 0.0 & -3.6 & 8.1 \\
26 & 8 & 7 & 5.2 & -11.4 & 11.5 & 1.6 & 0.0 & -4.0 & 9.7 \\
27 & 12 & 7 & 6.6 & -13.2 & 14.3 & 2.0 & -0.1 & -4.4 & 12.0 \\
28 & 4 & 6 & 2.6 & -6.2 & 5.7 & 0.7 & -0.1 & -2.4 & 4.8 \\
29 & 7 & 6 & 4.0 & -9.2 & 9.2 & 1.2 & 0.0 & -3.2 & 7.6 \\
30 & 10 & 6 & 5.8 & -10.8 & 12.0 & 1.7 & -0.1 & -3.5 & \\
\hline 31 & 3 & 7 & 2.5 & -6.1 & 5.2 & 0.7 & 0.0 & -2.4 & \\
32 & 4 & 10 & 4.6 & -10.2 & 8.7 & 1.1 & -0.1 & -3.9 & \\
33 & 13 & 8 & 7.4 & -14.8 & 15.8 & 2.3 & 0.0 & -5.0 & 7.9 \\
\hline
\end{tabular}

Table A.3 - Percent differences respect to the baseline case of instantaneous cumulative ebb discharges for a spring tide, as a function of the two design variables (i.e. $x_{1}$ and $x_{2}$ ), obtained for each computational experiment defined in Fig. 8. The baseline ebb-discharge ratio between Armona and Faro-Olhão inlets is $35.8 \%$.

Differences in instantaneous cumulative ebb discharges [\%]

\begin{tabular}{|c|c|c|c|c|c|c|c|c|c|}
\hline Case & $\begin{array}{c}x_{1} \\
\text { [rows] }\end{array}$ & $\begin{array}{c}x_{2} \\
{[\text { TECs/row] }}\end{array}$ & Ancão & $\begin{array}{l}\text { Faro- } \\
\text { Olhão }\end{array}$ & Armona & Fuseta & Tavira & All inlets & $\begin{array}{l}\text { Ratio } \\
\text { Ar/FO }\end{array}$ \\
\hline 1 & 1 & 11 & 0.5 & -0.9 & 0.1 & -0.1 & 0.0 & -0.5 & 0.4 \\
\hline 2 & 13 & 11 & 3.0 & -12.5 & 6.8 & -0.6 & -0.1 & -5.2 & 7.9 \\
\hline 3 & 13 & 6 & 1.3 & -5.9 & 3.3 & -0.4 & 0.0 & -2.5 & 3.5 \\
\hline 4 & 1 & 6 & 0.1 & -0.5 & 0.1 & -0.1 & 0.0 & -0.3 & 0.2 \\
\hline 5 & 4 & 11 & 1.4 & -5.6 & 1.8 & -0.4 & -0.1 & -2.6 & 2.8 \\
\hline 6 & 7 & 11 & 2.0 & -10.4 & 4.2 & -0.4 & -0.1 & -4.7 & 5.8 \\
\hline 7 & 10 & 11 & 2.6 & -12.2 & 5.7 & -0.5 & -0.1 & -5.3 & 7.3 \\
\hline 8 & 2 & 10 & 0.7 & -3.5 & 0.7 & -0.4 & -0.1 & -1.7 & 1.6 \\
\hline 9 & 6 & 10 & 1.4 & -8.6 & 3.3 & -0.3 & 0.0 & -3.9 & 4.7 \\
\hline 10 & 8 & 10 & 1.8 & -9.9 & 4.3 & -0.4 & -0.1 & -4.4 & 5.7 \\
\hline 11 & 12 & 10 & 2.7 & -11.2 & 6.1 & -0.6 & -0.1 & -4.7 & 7.0 \\
\hline 12 & 3 & 9 & 0.4 & -2.9 & 0.4 & -0.4 & -0.1 & -1.5 & 1.2 \\
\hline 13 & 5 & 9 & 1.1 & -6.3 & 2.4 & -0.4 & 0.0 & -2.9 & 3.3 \\
\hline 14 & 7 & 9 & 1.4 & -8.2 & 3.4 & -0.4 & 0.0 & -3.7 & 4.5 \\
\hline 15 & 9 & 9 & 1.9 & -9.3 & 4.2 & -0.5 & -0.1 & -4.1 & 5.4 \\
\hline 16 & 11 & 9 & 2.4 & -9.8 & 5.1 & -0.6 & -0.1 & -4.2 & 5.9 \\
\hline 17 & 13 & 9 & 1.5 & -10.1 & 5.5 & -0.5 & -0.1 & -4.3 & 6.2 \\
\hline 18 & 1 & 8 & 0.2 & -0.7 & 0.2 & -0.1 & 0.0 & -0.3 & 0.3 \\
\hline 19 & 3 & 8 & 0.2 & -2.4 & 0.2 & -0.4 & 0.0 & -1.2 & 0.9 \\
\hline 20 & 5 & 8 & 0.9 & -5.3 & 2.0 & -0.3 & 0.0 & -2.4 & 2.8 \\
\hline 21 & 7 & 8 & 0.9 & -5.3 & 2.0 & -0.3 & 0.0 & -2.4 & 2.8 \\
\hline 22 & 9 & 8 & 1.6 & -8.1 & 3.6 & -0.4 & -0.1 & -3.6 & 4.6 \\
\hline 23 & 11 & 8 & 2.2 & -8.6 & 4.4 & -0.5 & -0.1 & -3.6 & 5.1 \\
\hline 24 & 2 & 7 & 0.4 & -1.8 & 0.1 & -0.4 & 0.0 & -0.9 & 0.7 \\
\hline 25 & 6 & 7 & 1.1 & -5.0 & 2.2 & -0.3 & 0.0 & -2.2 & 2.7 \\
\hline 26 & 8 & 7 & 1.2 & -6.3 & 2.9 & -0.3 & 0.0 & -2.8 & 3.5 \\
\hline 27 & 12 & 7 & 1.5 & -7.3 & 4.0 & -0.5 & -0.1 & -3.1 & 4.4 \\
\hline 28 & 4 & 6 & 0.3 & -2.1 & 0.5 & -0.3 & 0.0 & -1.0 & 0.9 \\
\hline 29 & 7 & 6 & 0.6 & -4.6 & 2.0 & -0.4 & 0.0 & -2.1 & 2.5 \\
\hline 30 & 10 & 6 & 1.5 & -5.5 & 2.7 & -0.4 & -0.1 & -2.4 & 3.1 \\
\hline 31 & 3 & 7 & 0.4 & -1.8 & 0.1 & -0.4 & 0.0 & -0.9 & 0.7 \\
\hline 32 & 4 & 10 & 1.0 & -4.9 & 1.6 & -0.4 & 0.0 & -2.3 & 2.5 \\
\hline 33 & 13 & 8 & 1.9 & -8.7 & 4.8 & -0.5 & -0.1 & -3.7 & 5.3 \\
\hline
\end{tabular}




\section{Pre-print}

Table A.4 - Net volume changes and average depth differences respect to the baseline case for the Faro-Olhão flood delta $\left(V_{f}\right)$ and the Armona inlet, as a function of the two design variables (i.e. $x 1$ and $x 2$ ), obtained for each computational experiment defined in Fig. 8.

\begin{tabular}{|c|c|c|c|c|c|c|}
\hline \multirow[b]{2}{*}{ Case } & \multirow[b]{2}{*}{$x_{1}[$ rows] } & \multirow[b]{2}{*}{$x_{2}[$ TECs/row] } & \multicolumn{2}{|c|}{ Net volume change $\left[\mathrm{m}^{3}\right]$} & \multicolumn{2}{|c|}{ Avg. difference of $\Delta h[\mathrm{~cm}]$} \\
\hline & & & Faro-Olhão $\left(V_{f}\right)$ & Armona & Faro-Olhão $\left(V_{f}\right)$ & Armona \\
\hline 1 & 1 & 11 & -4090 & 7020 & -0.6 & 0.0 \\
\hline 2 & 13 & 11 & -4228 & 13865 & -3.3 & 3.2 \\
\hline 3 & 13 & 6 & -4270 & 20067 & -2.9 & 21.1 \\
\hline 4 & 1 & 6 & -4290 & 25970 & -0.6 & 14.4 \\
\hline 5 & 4 & 11 & -9475 & 33262 & 0.7 & 1.7 \\
\hline 6 & 7 & 11 & -14581 & 40019 & -1.5 & 10.2 \\
\hline 7 & 10 & 11 & -19480 & 45958 & -3.5 & 15.7 \\
\hline 8 & 2 & 10 & -21670 & 51061 & -0.4 & 19.6 \\
\hline 9 & 6 & 10 & -23390 & 55392 & -1.0 & 7.7 \\
\hline 10 & 8 & 10 & -24660 & 59022 & -2.6 & 13.7 \\
\hline 11 & 12 & 10 & -25030 & 61990 & -3.4 & 16.1 \\
\hline 12 & 3 & 9 & -25116 & 64285 & -0.5 & 19.9 \\
\hline 13 & 5 & 9 & -24980 & 65940 & -1.0 & 7.0 \\
\hline 14 & 7 & 9 & -5267 & 14967 & -1.8 & 11.3 \\
\hline 15 & 9 & 9 & -6320 & 23120 & -3.2 & 13.8 \\
\hline 16 & 11 & 9 & -6349 & 23260 & -3.2 & 16.3 \\
\hline 17 & 13 & 9 & -8375 & 30828 & -3.1 & 18.2 \\
\hline 18 & 1 & 8 & -11465 & 38873 & -0.6 & 18.8 \\
\hline 19 & 3 & 8 & -15360 & 47060 & -0.5 & 2.3 \\
\hline 20 & 5 & 8 & -18901 & 51599 & -1.1 & 6.2 \\
\hline 21 & 7 & 8 & -23020 & 57590 & -1.1 & 10.3 \\
\hline 22 & 9 & 8 & -24723 & 62020 & -3.2 & 10.3 \\
\hline 23 & 11 & 8 & -25767 & 66236 & -3.1 & 15.1 \\
\hline 24 & 2 & 7 & -26275 & 69897 & -0.5 & 16.9 \\
\hline 25 & 6 & 7 & -26730 & 73260 & -1.5 & 5.4 \\
\hline 26 & 8 & 7 & -26548 & 75267 & -2.6 & 10.5 \\
\hline 27 & 12 & 7 & -4970 & 9620 & -3.2 & 12.7 \\
\hline 28 & 4 & 6 & -5760 & 18247 & -0.1 & 15.9 \\
\hline 29 & 7 & 6 & -6840 & 26760 & -2.1 & 6.0 \\
\hline 30 & 10 & 6 & -9598 & 36550 & -3.0 & 10.2 \\
\hline 31 & 3 & 7 & -12650 & 46180 & -0.5 & 13.1 \\
\hline 32 & 4 & 10 & -12839 & 47019 & 0.5 & 5.4 \\
\hline 33 & 13 & 8 & -12650 & 46180 & -3.0 & 9.4 \\
\hline
\end{tabular}

